\title{
Entre soft power e sharp power: A diplomacia pública da China durante o combate à pandemia de COVID-19
}

\author{
Between soft power and sharp power: \\ China's public diplomacy in the fight against COVID-19 pandemic
}

\author{
Niedja de Andrade e Silva Forte dos Santos* \\ Sandra Maria Rodrigues Balão**
}

*Instituto Superior de Ciências Sociais e Políticas, Portugal; Email: niedjasantos@edu.ulisboa.pt

**Instituto Superior de Ciências Sociais e Políticas, Portugal; Email: sbalao@iscsp.ulisboa.pt

\begin{abstract}
RESUMO
A investigação objetiva identificar como a China articulou ações de soft e sharp power durante a pandemia de COVID-19. O argumento central é o de que a articulação entre soft e sharp power é uma característica inerente à diplomacia pública chinesa. Neste particular o sharp power é apresentado como um estilo de poder que opera não só na dimensão internacional, mas também na doméstica. Após contextualizar a China, a matriz analítica é construída a partir da operacionalização dos conceitos de diplomacia pública, soft power e sharp power, destacando as características chinesas. O estudo de caso foi adotado como método de investigação, sendo os dados colhidos em fontes primárias e secundárias. A conclusão sumariza a forma pela qual a China articulou ferramentas de diplomacia pública mesclando o sharp e o soft power, com êxito quanto ao controle da pandemia e projeção positiva na esfera internacional, não obstante alguma crítica emergente. A pesquisa sugere a incorporação do sharp power ao acervo diplomático global como um caminho possível, além de indicar vias para futuros desenvolvimentos.
\end{abstract}

Palavras-chave: China; COVID-19; sharp power, soft power; diplomacia pública 


\section{ABSTRACT}

The research aims to identify how China articulated soft and sharp power while fighting the COVID-19 pandemic. The main argument is that the articulation between soft and sharp power is an inherent characteristic of Chinese public diplomacy. This argument features soft power as a power style operating not only in the international dimension, but also in the domestic dimension. After China's contextualization, the analytical matrix was built from the operationalization of key concepts, namely public diplomacy, soft power and sharp power, paying attention to Chinese characteristics. The case study was led with data collected from primary and secondary sources. Besides the indication of paths for future developments, the conclusion summarizes how Chinese public diplomacy managed soft and sharp power with positive results in the international sphere and suggests that incorporating sharp power to diplomatic toolbox may be useful.

Keywords: China; COVID-19; soft power; sharp power; public diplomacy

\section{Introdução}

"In the face of a previously unknown virus, China has rolled out perhaps the most ambitious, agile and aggressive disease containment effort in history". A distinção pública internacional à China foi conferida pela World Health Organization (WHO) após a missão técnica internacional realizada no país no início da pandemia, em fevereiro de 2020 (WHO, 2020a, p. 16). Como primeiro país a enfrentar o desafio sanitário, a China obteve êxito no controle da pandemia em pouco mais de dois meses, conforme declaração oficial da WHO em março de 2020 (Ghebreyesus, 2020).

As ações domésticas conduzidas pela China internacionalizaram-se à medida que a COVID-19 avançava pelo mundo. A cooperação internacional foi fortalecida, sobretudo no campo científico. A título de exemplo, a sequência genómica do novo vírus foi compartilhada pela China com a comunidade internacional em janeiro de 2020, antes do reporte dos primeiros casos de contaminação pelo vírus fora da China (WHO, 2020b). A intensa interação internacional ocorreu através de ações diplomáticas ligadas à science diplomacy (Melchor, 2020), como as denominadas mask diplomacy (Verma, 2020), vaccine diplomacy (Oxford Analytica, 2021) e health diplomacy (Fazal, 2020), conjunto que foi estudado até mesmo sob o título coronavirus diplomacy (Kobierecka \& Kobierecki, 2021). A importância das políticas domésticas para o soft power e a diplomacia pública já havia sido identificada por autores como Nye (2004, 107-117; 2019, 12-15) e Leonard (2002, 8-21) no início do século XXI. De forma similar, Walker ressaltou que o estilo sharp power, presente nos valores repressivos de sistemas autoritários, são projetados internacionalmente (Walker, 2018, p. 19). Na verdade, a diplomacia pública produz preferred outcomes a partir da conversão de recursos nacionais básicos em políticas, iniciativas e 
programas (shaped resources) que são articulados através de estratégias habilidosas de conversão de poder em resultados (2011, pp. 99-100). Nesta linha, esta investigação apresenta o soft e o sharp power como os principais orientadores estratégicos da diplomacia pública chinesa durante a pandemia de COVID-19. Durante a emergência sanitária, eventos internacionais, contatos diretos e trocas culturais, as quais operam preponderantemente na dimensão internacional da diplomacia pública, permaneceram inviabilizados. Desta forma, medidas sanitárias como confinamento, distanciamento social e restrições à mobilidade trouxeram consigo maior atenção da comunidade internacional, a partir da conversão de ações, estratégias e políticas domésticas de cada Estado em resultados de diplomacia pública.

Com efeito, atividades chinesas como protocolos de tratamento e diagnóstico e pesquisas sobre vacinas ganharam relevância no contexto da diplomacia pública; neste caso, com características de soft power. Da mesma forma, providências como o rastreamento tecnológico, uso de máscaras e testagem obrigatória de cidadãos e estrangeiros, bem como o confinamento mandatório, que foram apontadas como autoritárias (Graham-Harrison \& Kuo, 2020; Campbell \& Doshi, 2020; Tufekci, 2020), enquadráveis sob o conceito de sharp power na esfera da diplomacia pública (Santos, 2020a), foram parte integrante do bem sucedido combate pandêmico chinês. Tais medidas, além de terem sido reconhecidas como eficazes pela ciência (Bradshaw, Alley, Huggins et al., 2021; Wilder-Smith \& Freedman, 2020), foram replicadas por diversos outros países que vieram, posteriormente, a enfrentar a pandemia. Desta forma, sob a perspectiva da diplomacia pública, a amplamente reconhecida eficácia da China no controle da pandemia de COVID-19 (The Lancet, 2020; Castañón \& Esomonu, 2020; AlTakarli, 2020; Cyranoski 2020) foi composta por um conjunto de ações de soft e sharp power, aplicadas tanto no nivel doméstico quanto internacional.

Neste contexto, o objetivo do artigo é investigar a diplomacia pública da China, respondendo à questão de pesquisa: de que forma as ações de combate à pandemia de COVID-19 promovidas pela China representam, no âmbito da diplomacia pública, uma articulação bem sucedida entre o soft power e o sharp power? Para tal mister, é conduzido o estudo de caso (Yin, 2018), composto por dados colhidos em fontes primárias e secundárias. $\mathrm{O}$ argumento central é o de que a articulação entre o soft power e o sharp power, que já foi apontada em trabalhos anteriores como uma característica própria da diplomacia pública chinesa (Santos, 2019, p. 96; Santos, 2020a), também foi fundamental para o bem sucedido enfrentamento chinês do desafio pandêmico, contexto em que a diplomacia pública foi alicerçada principalmente pelas políticas domésticas convertidas em poder com impacto internacional. 
Não obstante os estudos já realizados sobre o uso do poder autoritário durante a pandemia (Zhao S., 2020), bem como as pesquisas sobre as diferenças na gestão da crise por países democráticos e autoritários (Alon, Farrell, \& Li, 2020), estudos específicos sobre a articulação entre soft e sharp power no contexto da diplomacia pública durante a pandemia são escassos (Santos, 2020a). Assim, esta investigação procura preencher essa lacuna, evidenciando relevância científica.

Após a introdução, a China é contextualizada, seguindo-se a revisão bibliográfica, que traz à colação o estado da arte da diplomacia pública, do soft power e do sharp power, com atenção ao cenário chinês, que evidencia soft e sharp power operantes nas dimensões doméstica e internacional no combate à pandemia de COVID-19. Um dos outputs deste artigo é a definição inovadora que é apresentada para o conceito sharp power, considerando-o um poder não restrito a target countries, como inicialmente operacionalizado, mas operante entre as dimensões doméstica e internacional da política externa. A seção seguinte é dedicada à matriz analítica que guia a construção do estudo de caso, composta por variáveis e atributos de soft e sharp power, além das ferramentas de diplomacia pública. Então, o research design é detalhado, pavimentando o caminho para a apresentação do estudo de caso. No final, a conclusão demonstra a resposta à questão de pesquisa e indica caminhos para futuros desenvolvimentos, atingindo os objetivos da investigação.

\section{A China}

O “Reino do Meio" (Zhōngguó 中国), conhecido como China, é a segunda potência mundial, de acordo com a pesquisa da US News realizada anualmente em parceria com a Wharton School da University of Pennsylvania (US News, 2021). Independentemente das críticas da comunidade científica à metodologia do ranking (Haar, 2017), o facto é que a população e a economia chinesa colocam o país em posição de destaque global. Com 1,4 bilhões de habitantes, é o país mais populoso do planeta (World Bank [WB], 2021a). Na perspectiva económica, o PIB na casa dos US\$ 14 trilhões (WB, 2021b) é o maior da Ásia e o segundo no mundo, logo após os Estados Unidos.

Do ponto de vista político, é um "socialist state under the people's democratic dictatorship led by the working class" e pelo "principle of democratic centralism" (People's Republic of China [PRC], 2004, art. 1, 3). Desde a revolução que se seguiu à guerra civil (Guógòng nèizhàn 国共内战) nos anos de 1940, o país segue sob o domínio político do Partido Comunista da China (CPC) (Zhōngguó Gòngchăndăng 中国共产党). Apesar da Constituição da República Popular da China (Zhōnghuá Rénmín Gònghéguó Xiànfă 中华人民共和国宪法) adotar o sistema multipartidário e não mencionar o CPC (PRC, 2004, art. 5), o partido 
está interligado com a estrutura do governo com forte poder institucional. Xi Jinping, presidente da PRC desde 2013, ocupa o mais alto posto do CPC: o de secretário-geral (Zhōnggòng zhōngyāng zǒng shūjì 中共中央总书记). O Conselho de Estado (Zhōngyāng rénmín zhèngfǔ zhèngwùyuàn 中央人民政府政务院) é a principal autoridade administrativa da China, sendo comandado pelo premier (Li, 2019, pp. 210-214; Fernandes, 2014, pp. 8-18; PRC, 2004; CPC, 2017).

A referência à ditadura na constituição e a forte presença do CPC na estrutura política, frequentemente levam à ilação de que a China é dominada por um poder omnipresente, altamente centralizador e autocrático (Nye, 2019, p. 8). Neste contexto em particular, o índice da democracia da The Economist, que tem classificado a China entre os 20 países menos democráticos entre 167 analisados (2021, p. 13) tem assumido um papel de particular relevância. Entretanto, as referências teóricas às autocracias (Danziger \& Smith, 2015, pp. 168-176; Hague, Harrop, \& McCormick, 2016, pp. 343-349) não explicam plenamente o modelo chinês, em que o poder político não opera apenas na direção top-down, verificando-se a existência de um modelo de governança multinível, inclusive com participação de atores não estatais (Hensengerth \& Lu, 2018; Jing, 2015, p. 2; Santos, 2021a). Destarte, variações do regime autocrático caracterizadas pela comunicação multidirecional, poderes legislativo e judiciário ativos, eleições e utilização de novos media, entre outros aspetos (Levitsky \& Way, 2002, pp. 54-58) vêm sendo explicadas sob padrões conhecidos como "competitive authoritarianism" (Levitsky \& Way, 2002, p. 60), "pluralised authoritarianism" (Lewis, 2013, p. 681), "managed pluralism" (Balzer, 2003), "decentralized authoritarianism" (Landry, 2008), "resilient authoritarian" (Hensengerth, 2015), "autocracy with chinese characteristics" (Ang, 2018), entre outros. De fato, pode ser atribuído à China um regime político próprio/com características chinesas.

$\mathrm{Na}$ verdade, a organização política da PRC é complexa, com expressiva descentralização interna. Os poderes legislativo, judiciário e executivo estão disseminados em diversos níveis subnacionais a partir do governo central. Outrossim, a abertura económica (găigé kāifàng 改革开放), a partir de 1976, complementando o socialismo com a economia de mercado, fomentou um ambiente pluralístico (Fulda, Li, \& Song, 2009). Atores estatais subnacionais, líderes empresariais e representantes da academia, think tanks e ONGs (Hensengerth, 2015, p. 304) passaram a influenciar a construção e implementação de políticas (Changhe, 2010), forçando a difusão de poder (Jing, 2015, p. 2; Hess, 2013, pp. 81-82; Hensengerth \& Lu, 2018, p. 2). O modelo, que veio acompanhado de sucesso económico (D'Hooghe, 2014, pp. 67-69), inspirou a criação da expressão "Beijing Consensus" em contraponto ao "Washington Consensus" (Ramo, 2004; Kennedy, 2010). A conjuntura tem sido autodenominada 
“socialismo com características chinesas" (Zhōngguó tèsè shèhuì zhǔyì sīxiăng 中国特色社会主义思想) (Keqiang, 2020).

A fragmentação de poder na China foi uma das fragilidades identificadas durante o combate à SARS em 2003, o que colocou a postura autoritária como fator decisivo no enfrentamento do surto (Wong \& Yongnian, 2004, pp. 4, 9). Como constataram Yongnian \& Fook, "national resources were mobilized to deal with the outbreak...[and] to a large extent, the authoritarian nature of the Chinese political system enabled the top leadership to implement quite effective measures to bring SARS under control" (2004, p. 62). Nomeadamente, o Comitê Permanente do Congresso Nacional do Povo (Zhōnghuá rénmín gònghéguó quánguó rénmín dàibiǎo dàhuì chángwù wěiyuánhuì 中华人民共和国全国人民代表大会常务委员 会) criou a força tarefa nacional coordenada pelo premier (Yongnian \& Fook, 2004, p. 62). Dezassete anos depois, as lessons learned inspirariam o plano de enfrentamento à pandemia de COVID-19 (Cooper, 2020), conforme ficará demonstrado no estudo de caso.

\section{Enquadramento teórico}

Para pavimentar o caminho conducente ao enquadramento analítico, é fundamental compreender os conceitos relacionados com a temática. Assim, esta secção é dedicada à revisão bibliográfica em torno da diplomacia pública, do soft power e do sharp power, com foco nas peculiaridades chinesas. O objetivo é operacionalizar tais conceitos em variáveis e atributos, bem como evidenciar que se trata de estilos de poder que operam tanto na dimensão doméstica quanto internacional.

\subsection{Diplomacia pública}

Por volta de 500 a.C., durante a dinastia Zhou (Zhōu cháo 周朝) na China, ocorria a transição do tribalismo para o arranjo com estrutura administrativa e militar (Lau, 2019, pp. 4-5; Fukuyama, 2013, pp. 56-57). Neste cenário, Confúcio (Kǒngž̌ 孔子) propunha que a atração e influência de outros povos ocorresse por políticas consistentes e pela força moral do governante, preferencialmente à ação militar (Confúcio, 2019, p. 115). O princípio está associado à atual noção de diplomacia pública, relativa à arte de atrair e influenciar internacionalmente (Melissen \& Wang, 2019, p.1; Nye, 2019, p. 11). Contudo, a primeira utilização do termo associado à influência de políticas internacionais através da opinião pública (Gilboa, 2015, p. 1) tem origem ocidental e é creditada ao norte-americano Edmund Gullion (Mendes, 2017, p. 160; Cull, 2020, p. 13).

Nos anos de 1980, com a intensificação dos primeiros estudos sobre o tema, Malone definiu-a como "direct communication with foreign peoples, with the aim 
of affecting their thinking and, ultimately, that of their governments (1985, p. 199). Mais recentemente, a definição de Snow, evidencia a relação da diplomacia pública com o poder global e a busca por legitimidade: "management of persuasion and social influence in the service of international legitimacy" (2020, p. 4). Já no final do século xx, a diplomacia pública ganhou força no ocidente como comunicação oficial destinada a públicos estrangeiros (Melissen, 2005, pp. 3, 6; Nye, 2008, p. 101), com o objetivo de alavancar interesses e valores dos Estados (Sharp, 2005, p. 106). Especialmente após o 11 de setembro, a construção de relacionamentos de longo prazo e o envolvimento de públicos estrangeiros passaram a ser os principais alvos da "nova diplomacia pública".

Entretanto, a partir de 2020, as restrições e necessidades decorrentes da pandemia da COVID-19 contribuíram para a prevalência do pilar das políticas domésticas da diplomacia pública que, são uma reconhecida e importante fonte de soft power no contexto da diplomacia pública (Nye, 2004, 107-117; 2019; Leonard, 2002, 8-21). Este artigo argumenta que, da mesma forma, o sharp power tem estreita relação com as políticas internas. Em tais hipóteses, as medidas passam por estratégias de conversão do poder no processo de diplomacia pública, tais como a mediated public diplomacy, especialmente quando se pretende atingir uma "vast majority of foreign citizens" (Golan, Manor, \& Arcenaux, 2019, pp. 3-6). Desta forma, políticas domésticas, como protocolos de tratamento da COVID-19 são convertidas em resultados na esfera internacional a partir do direcionamento estratégico conferido pelos estilos de poder. Neste caso, nomeadamente o soft e o sharp power (ver Figura 1).

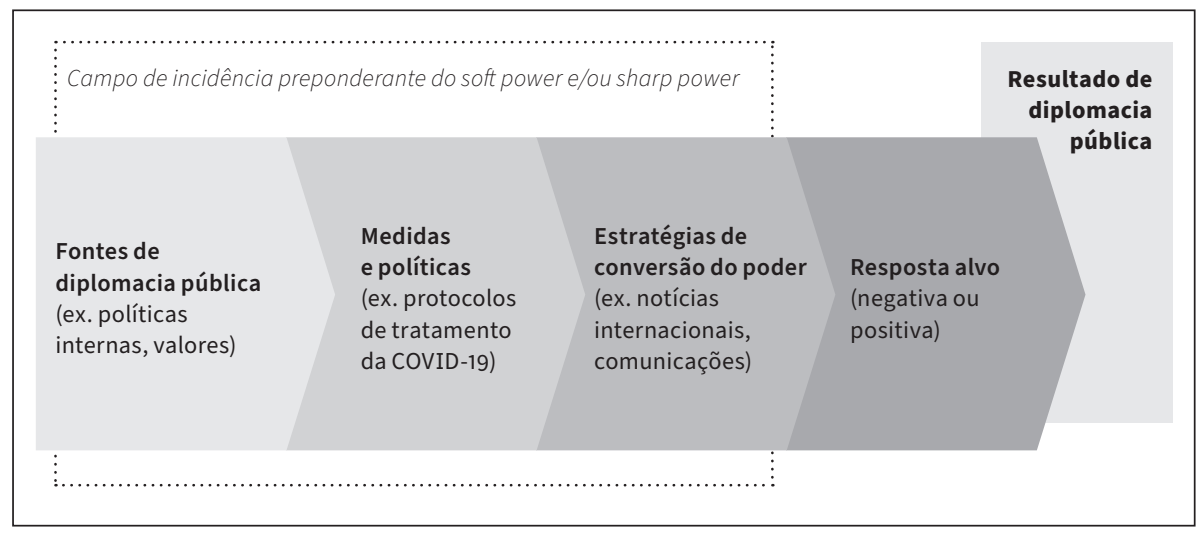

\section{FIGURA 1}

Representação gráfica do campo de incidência do soft power e do sharp power para conversão de recursos básicos em resultados de diplomacia pública 
Enquanto a diplomacia tradicional compreende relações de governo para governo $(\mathrm{G} 2 \mathrm{G})$, a diplomacia pública é o diálogo entre o governo e públicos globais (G2P), visando envolvê-los e comprometê-los nos objetivos da política externa (Snow, 2009, p. 6). Já a nova diplomacia pública está relacionada com a influência exercida sobre a política externa pelo governo e por atores privados (P2P) (Snow, 2009, p. 6). Desta forma, a diplomacia pública sobrepôs-se à centralidade da diplomacia tradicional (Jesus, 2014, p. 152), como medida pacífica de política externa (Mendes, 2017, p. 154; Magalhães, 1982, pp. 11-19).

Muito embora Nye seja popular entre estudiosos chineses (Haixia, 2017, pp. 13) e Melissen seja frequentemente citado por autores da diplomacia na China (Zhao K. \& Chen, 2013, p. 62), o estudo das relações internacionais no país é frequentemente enquadrado por teorias específicas. Exemplificativamente, a Tianxia (天下) ou “tudo abaixo dos céus", baseada no confucionismo, norteia a iniciativa chinesa da Silk Road, proclamando um sistema internacional em que o mundo é um sujeito político e não algo a ser conquistado e dominado. A teoria substitui a variável da anarquia internacional pelo equilíbrio dinâmico do yin yang (阴阳) na ordem internacional (Zhao T., 2018). Assim, é importante que a diplomacia chinesa e suas particularidades sejam analisadas a partir de um ponto de vista fixo. A presente pesquisa adota o referencial teórico elaborado por Cull.

Cull definiu a diplomacia pública como "listening to the other side and working to develop a relationship of mutual understanding” e particularizou cinco variáveis: listening, advocacy, diplomacia cultural, intercâmbios e internacional broadcasting (2019, p. 23). O padrão proposto por Cull vem sendo amplamente adotado (Hartig, 2019, p. 1; Velikaya \& Simons, 2020, p. 9; Goff, 2020, p. 30; Santos, 2020b). Listening é o mecanismo de envolvimento com o público internacional através da compreensão de expetativas (Cull, 2019, pp. 38-45). A advocacy corresponde à defesa internacional de argumentos, políticas e narrativas (Cull, 2019, pp. 49-61). A diplomacia cultural é disseminação de mensagens através da cultura (Cull, 2019, pp. 64-73), enquanto que os intercâmbios englobam a receção ou o envio de cidadãos ao exterior, com finalidades variadas (Cull, 2019, pp. 77-84). Por fim, international broadcasting é a transmissão internacional de notícias em larga escala (Cull, 2019, pp. 87-103). A Tabela 1 traz exemplos de ferramentas de tais variáveis. 


\section{TABELA 1}

Exemplos de ferramentas de diplomacia pública conforme matriz de Cull (2019)

\begin{tabular}{|c|c|}
\hline VARIÁVEIS & FERRAMENTAS/INSTRUMENTOS ${ }^{[1]}$ \\
\hline Listening & $\begin{array}{l}\text { Relatórios de inteligência, pesquisas, métricas de envolvimento em redes sociais, } \\
\text { contatos com os media locais, análise de pesquisas académicas, data mining, } \\
\text { resumos de editoriais internacionais, análise de discursos em rádio, reação de } \\
\text { audiência, análise de big data, turnée internacional de escuta (Cull, 2019, pp. 38-45; } \\
\text { Martino, 2020, pp. 23-25). }\end{array}$ \\
\hline Advocacy & $\begin{array}{l}\text { Narrativas, discursos, políticas, mensagens diretas, cartas abertas, redes sociais, } \\
\text { press releases, think tanks, diplomacia do cidadão, de diáspora e de celebridades, } \\
\text { campanhas, mensagens multimeios (filmes, rádio, poemas, cartoons, etc.), ajuda } \\
\text { internacional (Cull, 2019, pp. 49-61; Leonard, 2002, pp. 14-18; Gilboa, 2008, pp. 72-73). }\end{array}$ \\
\hline $\begin{array}{l}\text { Diplomacia } \\
\text { cultural }\end{array}$ & $\begin{array}{l}\text { Festivais, exposições, teatro, bibliotecas, vídeo, moda, música, arte, caligrafia, } \\
\text { fotografias, arquitetura, institutos culturais no exterior, high culture, diplomacia } \\
\text { desportiva, gastronomia, diplomacia da fé ou religiosa (Cull, 2019, pp. 64-73; Goff, } \\
\text { 2020, pp. 31-34; Gilboa, 2008, pp. 72-73). }\end{array}$ \\
\hline Intercâmbios & $\begin{array}{l}\text { Intercâmbios educacionais, visitas técnicas e com objetivo de participação } \\
\text { em conferências, intercâmbios de jovens, militares e profissionais, instituições } \\
\text { mediadoras de intercâmbio internacional, intercâmbios online, que incluem as } \\
\text { conferências virtuais, voluntariado, turismo (Cull, 2019, pp. 77-84; Scott-Smith, 2020, } \\
\text { pp. 42-46; Leonard, 2002, pp. 18-20) }\end{array}$ \\
\hline $\begin{array}{l}\text { International } \\
\text { broadcasting }\end{array}$ & $\begin{array}{l}\text { Rádio, agências de notícias, websítios, podcasts, filmes, redes sociais, emissoras de } \\
\text { TV e jornais internacionais, surrogate broadcasting, (Cull, 2019, pp. 87-103; Arceneaux } \\
\text { \& Powers, 2020, pp. 52-59; Leonard, 2002, pp. 12-14; Gilboa, 2008, pp. 72-73) }\end{array}$ \\
\hline
\end{tabular}

Fonte: tabela elaborada pelas autoras a partir dos autores e obras referenciados.

\subsection{A diplomacia pública chinesa}

"Diplomacia pública com características chinesas" (Zhōngguó tèsè gōnggòng wàijiāo 中国特色公共外交) é uma definição que evidencia a singularidade da China neste campo (Weiwei, 2009; Hartig, 2012). Sucintamente, D’Hooghe enumera as principais particularidades da diplomacia pública chinesa: o crescimento económico exponencial, a cultura não ocidental, o sistema autocrático, o controle das redes sociais, o desafio que impõe à posição hegemónica dos EUA, a imagem negativa de turistas chineses no exterior e as questões ambientais (2014, pp. 7, 53-56, 90-91). Tal cenário deu origem a um novo modelo na ordem política estabelecida (Zhao K., 2016), que segue um caminho mais funcional e pragmático do que normativo, sempre alinhado com

1. Adiante, as palavras ferramentas e instrumentos são usadas indistintamente. 
os interesses nacionais (Hartig, 2019, p. 2; D’Hooghe, 2014, pp. 6-8). O modelo estadocêntrico (D’Hooghe, 2014, p. 6), alicerça a diplomacia pública chinesa na perspectiva predominantemente realista, (Haixia, 2017, p. 11), especificamente realista neoclássica (Santos, 2019), que se aproxima do modelo G2P descrito por Snow (2009, p. 6), mas ao qual acrescem particularidades.

O governo nacional é o ator central da diplomacia pública chinesa. Os líderes políticos, presidente e premier, destacam-se como protagonistas. Entre os coadjuvantes, agem o Ministério das Relações Exteriores (Zhōnghuá Rénmin Gònghéguó Wàijiāobù 中华人民共和国外交部), as embaixadas e missões chinesas no exterior, o Gabinete de Informações do Conselho de Estado (Guówùyuàn Xīnwén Bàngōngshì 國務院新聞辦公室), outros ministérios, especialmente o Ministério da Cultura e Turismo (Wénhuà hé lüyóu bù 文化和旅 游部), que fomenta centros culturais no exterior e o websítio "china.culture. org”, além do Exército de Libertação Popular (Rénmín jiěfàngjūn 人民解放军) (D’Hooghe, 2014, pp. 133-150). 'Entrelaçado' com o governo chinês, o CCP, com departamento internacional próprio e com o organizado sistema de spokespersons ( fāyán rén发言人), relaciona-se ativamente com mais de 400 partidos políticos pelo mundo (Chen N., 2011; D’Hooghe, 2014, pp. 151; Luan \& Sun, 2012).

Com a abertura económica, novos agentes emergiram. Verticalmente, entes subnacionais como províncias (shěng 省) e municípios (xiàn 县) tornaram-se relevantes agentes diplomáticos. Horizontalmente, multiplicaram-se os sujeitos não estatais, nomeadamente empresas multinacionais, organizações não governamentais, como a agência de ajuda Cruz Vermelha da China (Zhōngguó hóng shízi huì 中国红十字会). Nesse grupo insere-se também a elite académica, incluindo universidades e think tanks (zhìnáng tuán 智囊团), bem como voluntários e celebridades (Postema \& Melissen, 2021). A diáspora chinesa (huáqiáo华侨,華僑) também tem revelado o seu potencial como agente diplomático, tanto que o Conselho de Estado criou uma agência para a atenção (gestão) aos (de) chineses no exterior: o Gabinete de Assuntos Chineses U1tramarinos (Guówùyuàn qiáowù bàngōngshì 国务院侨务办公室) (Yilong, 2012), o qual é mais uma evidência do uso de políticas domésticas a favor do sharp power.

A perceção do país quanto ao poder da influência internacional despertou nos anos de 1970 e a sua história evidencia o caminho evolutivo das políticas externas da China. Na arena académica, foram precursores os estudos sobre “poder nacional abrangente” (Zònghé guóli综 合国力). De modo unânime, estudiosos chineses apontavam o peso de fatores intangíveis como cultura, educação e habilidades diplomáticas para o poder nacional abrangente chinês (Haixia, 2017, pp. 5-7). Constituía padrão a visão subestimada de especialistas 
chineses sobre a posição geopolítica da China, evidenciando a baixa autoconfiança da elite académica (Haixia, 2017, pp. 7-8). Paralelamente, sob a liderança de Den Xiaoping, a China passou a ampliar a sua atuação internacional, pautada pela discrição e atitude esquiva relativamente à hegemonia (Glaubitz, 1976; Haixia, 2017, p. 15).

Entretanto, o crescimento exponencial da China, especialmente a partir dos anos 1990, passou a ser interpretado como ameaça ao equilíbrio global (Wang N., 2018, p. 125; Duggan, 2020, p. 174; Joseph, 2019, p. 19). A expressão "China threat" (Roy, 1996, p. 758) nasceu neste contexto, constituindo um exemplo de diplomacia destrutiva (Hartig, 2019, p. 8) em relação à China. D’Hooghe sugere que os investimentos da China em diplomacia pública teriam sido impulsionados justamente pela diplomacia pública destrutiva ocidental nos anos 1990 (2014, p. 68).

A partir do século xxI, observa-se a maior proatividade da China na diplomacia pública nas linhas reativa e defensiva. Jiang Zemin foi o primeiro presidente a exaltar o valor da diplomacia pública em 2008 (Ramsley, 2020, p. 286). Crises com repercussão internacional, como o surto de SARS em 2003 (Wong \& Yongnian, 2004), o escândalo dos brinquedos em 2007 (Lipton \& Barboza, 2007) e o terramoto de Sichuan em 2008 (Smith, 2018) impulsionaram a diplomacia pública reativa (D’Hooghe, 2014, pp. 11-12). De outro lado, ações diplomáticas defensivas como os jogos olímpicos de 2008 (Xu \& Cao, 2019) e a exposição universal de 2010 (Wang J., 2013) marcaram a inserção da diplomacia pública na agenda da política externa chinesa (D’Hooghe, 2014, pp. 74-81).

Esta fase foi permeada pelo conceito de "mundo harmonioso" (héxié shijjiè 和谐世界) (Jintao, 2005; 2007) ou “sociedade harmoniosa" (héxié shèhui 和谐社 会) (Ramsley, 2020, p. 286). O preceito sustentava-se em quatro premissas: (1) multilateralismo, (2) mecanismos de segurança coletiva, (3) prosperidade e cooperação com benefícios mútuos e (4) tolerância entre as nações (D’Hooghe, 2014, p. 81; Zheng \& Tok, 2007). O Instituto Confúcio (Kǒngzǐ xuéyuàn 孔子学 院), por exemplo, foi criado neste contexto, com o objetivo de promover uma sociedade mundial harmoniosa através da língua e cultura chinesas. ${ }^{[2]}$ Também foi inaugurada a Associação de Diplomacia Pública da China (CPDA) (Zhōngguó gōnggòng wàijiāo xiéhuì 中国公共外交协会), aspirando sacramentar a visão objetiva e abrangente da opinião pública internacional, desmistificando preconceitos, mal entendidos e dúvidas sobre a China (Jiechi, 2012). A iniciativa seguia a diretriz de intensificar a diplomacia pública e os intercâm-

2. O espírito da iniciativa, ligada à Tianxia (Zhao, 2018) faz uma ponte com a doutrina política do pacifismo (Balão, 2014, pp. 42-46) e apresenta paralelismo com a globalização pré-moderna a partir da era gâmica (Balão, 2014, pp. 118-133). 
bios culturais ( Wǒmen jiāng zhāshi tuījìn gōnggòng wàijiāo hé rénwén jiāoliú 我 们将扎实推进公共外交和人文交流), proferida por Hu Jintao no $18 .{ }^{\circ}$ Congresso Nacional do CPC (Jintao, 2012).

Com a posse de Xi Jinping em 2013, a narrativa "mundo harmonioso" cedeu lugar à do "sonho chinês" (zhōngguó mèng 中国梦), relacionado ao "grande rejuvenescimento da nação chinesa" (Zhōnghuá mínzú wěidà fùxīng 中华民族 伟大复兴) (Jinping, 2013a). Inicialmente, foi considerado um conceito vago e aberto, a possibilitar que cada cidadão invocasse sonhos pessoais (D'Hooghe, 2014, p. 83). Todavia, a estratégia "Cinturão Económico da Rota da Seda e a Rota da Seda Marítima do Século 21” (Sīchóu zhì lù jīngjì dài hé 21 shìjì hăishàng sīchóu zhī lù 丝绸之路经济带和21世纪海上丝绸之路) revelaria o “sonho chinês”. Ao divulgar a iniciativa "Um Cinturão Uma Rota" (One Belt One Road [OBOR]) (Yìdài yīlù 一带一路) através da diplomacia pública, em turnée internacional ao Casaquistão e Indonésia em 2013 (Costa, 2020, pp. 23-27), Xi Jinping explorou a política da "comunidade com futuro compartilhado para a humanidade" (Rénlèi mìngyùn gòngtóngtǐ 人类命运共同体) como diretriz para os laços entre a China e as nações do sudeste asiático (Jinping, 2013b), tornando transparente a prioridade da diplomacia regional (Hooghe, 2014, pp. 185-206; Ministry of Foreign Affairs of the People's Republic of China, 2017).

Posteriormente, além de expandida, a OBOR seria renomeada "Iniciativa Cinturão e Rota" (Belt and Road Initiative [BRI]) (Costa, 2020, p. 24). Para fomentá-la na Europa e África, Xi Jinping promoveu uma turnée internacional em 2018. Em 2019, a China reuniu 150 países no “2. ${ }^{\circ}$ Forum do Cinturão e Rota para a Cooperação Internacional" (Ėr jiè "yīdài yīlù" guójì hézuò gāofēng lùntán二届“一带一路”国际合作高峰论坛), que obteve 283 resultados práticos e somou mais de US\$ 64 bilhões em acordos de cooperação. Na ocasião, Xi Jinping reforçou que, com o objetivo de construir um futuro compartilhado para a humanidade, a BRI contempla a cooperação internacional com ampla consulta, para ampliar o fluxo comercial; fortalecer a conectividade terrestre, marítima, aérea e online; criar canais de logística e corredores comerciais, incluindo comboios China-Europa; desenvolver parques industriais e promover intercâmbios culturais (Jinping, 2019). Expressamente, Xi Jinping afirmou que "a construção conjunta da iniciativa "Belt and Road" tem origem na China mas gera oportunidades e resultados para o mundo" (wǒ duō cì shuōguò, gòng jiàn "yīdài yīlù" chàngyì yuán yú zhōngguó, jīhuì hé chéngguǒ shǔyú shìjiè 我多次 说过, 共建“一带一路”倡议源于中国, 机会和成果属于世界) (Jinping, 2019).

As principais realizações e medidas diplomáticas da BRI foram pontuadas pelo premier no relatório do governo apresentado em maio de 2020: realização de fora e encontros, advocacia em cimeiras internacionais como G2O e BRICS 
(summit diplomacy), diplomacia económica, discursos de líderes políticos, intercâmbios culturais e turnées políticas internacionais (Keqiang, 2020).

Adicionalmente, a revisão bibliográfica permite a identificação de outras ferramentas frequentemente verificadas na diplomacia pública chinesa: a diplomacia de primeira dama, exaltando principalmente moda, cultura e a abertura da China ao mundo (D'Hooghe, 2014, pp. 2-3; Wang N., 2018); festivais artísticos e culturais (D'Hooghe, 2014, p. 4), Instituto Confúcio (D’Hooghe, 2014, p. 4; Hartig, 2016); atividades internacionais da Xinhua, People's Daily, CCTV e CGTV (D’Hooghe, 2014, p. 4; Rawnsley, 2015; Cheng, Golan, \& Kiousis 2015; Rawnsley, 2020, p. 294; Madrid-Morales, 2017) e da Radio Internacional da China (CRI) (Zhōngguó guójì guăngbò diàntái 中国国际广播电台) (Chen \& Colapinto, 2010; Huang, 2018); novas redes sociais (D’Hooghe, 2014, pp. 166-168; Esarey \& Qiang, 2008); contas de broadcasters, spokespersons e representantes diplomáticos em redes sociais ocidentais (Madrid-Morales, 2017); media estrangeiros estabelecidos na China (D'Hooghe, 2014, pp. 168-170); institutos culturais chineses, como o de San Francisco (EUA), sendo que a BRI também fomenta a diplomacia cultural através do património histórico (D'Hooghe, 2014, pp. 171-173; Winter, 2016; Ramsley, 2020, pp. 288-289); diplomacia corporativa (Tang \& Li, 2011); ajuda internacional (D’Hooghe, 2014, pp. 179-180); e a diplomacia da cidade (Santos, 2020c). Tais ferramentas estão sumarizadas na Tabela 2.

O enfrentamento da COVID-19 é um capítulo importante da diplomacia pública chinesa. O desafio foi enfrentado a partir da visão de "comunidade com futuro compartilhado para a humanidade" (Sun, 2020; Jinsong, 2020), utilizando muitas das ferramentas de diplomacia pública descritas na Tabela 2. $\mathrm{O}$ estudo de caso demonstra que tais instrumentos foram enquadrados por habilidades associadas ao soft power e ao sharp power que influenciam, sobretudo, o modo de emprego e disseminação de medidas de combate à pandemia da COVID-19 a nível interno (Nye, 2019, 12-15; Walker, 2018, p. 19), bem como permeiam as estratégias de conversão do poder e sua projeção no nível internacional. Desta forma, o estudo situa o soft power e o sharp power como estilos incidentes sobre o processo de diplomacia pública da China durante a pandemia de COVID-19, que se inicia no plano doméstico antes de projetar-se para a dimensão internacional. 
TABELA 2

Principais ferramentas da diplomacia pública com características chinesas

\begin{tabular}{|c|c|}
\hline VARIÁVEIS & FERRAMENTAS/INSTRUMENTOS \\
\hline Listening & $\begin{array}{l}\text { Turnées políticas internacionais, rede de relacionamentos do CPC, realização } \\
\text { de fora e encontros, contatos diretos entre líderes políticos. }\end{array}$ \\
\hline Advocacy & $\begin{array}{l}\text { Discursos de líderes políticos, embaixadas e missões no exterior, spokespersons, } \\
\text { políticas ("futuro compartilhado para a humanidade"), estratégias (BRI), } \\
\text { narrativas ("sonho chinês", "grande rejuvenescimento da nação chinesa"), } \\
\text { CPDA, diplomacia da cidade, das celebridades e de summit, ajuda internacional, } \\
\text { investimentos na BRI. }\end{array}$ \\
\hline Diplomacia & Diplomacia de primeira dama, diáspora, diplomacia desportiva, Instituto \\
\hline cultural & $\begin{array}{l}\text { Confúcio, centros culturais chineses, websítio china.culture.org, intercâmbios } \\
\text { culturais, património histórico. }\end{array}$ \\
\hline Intercâmbios & $\begin{array}{l}\text { Diplomacia científica, académica e de voluntários, trocas internacionais } \\
\text { do CPC, diplomacia regional, realização de fora e encontros, diplomacia } \\
\text { económica, diplomacia corporativa. }\end{array}$ \\
\hline $\begin{array}{l}\text { International } \\
\text { broadcasting }\end{array}$ & $\begin{array}{l}\text { Xinhua, People's Daily, CCTV, CGTV, CRI, internet, redes sociais, media } \\
\text { estrangeiros na China. }\end{array}$ \\
\hline
\end{tabular}

Fonte: tabela elaborada pelas autoras a partir da subseção 3.2 deste artigo, com base na matriz de Cull (2019).

\subsection{Soft power}

A capacidade de influenciar determina o nível de interação do país na esfera internacional. Com efeito, a boa impressão junto do público estrangeiro pode determinar o nível de poder (Nye, 2019, p. 7) e o sucesso na atração de relacionamentos e alianças de longo prazo. O estilo soft power, conhecido na China por estratégia suave ou poder suave (ruăn shíli 软实力), força suave (ruăn lìliàng 软力 量), autoridade suave (ruăn quánli 软权力) ou poder suave nacional (ruăn guóli 软国力), tem a influência e a atração como variáveis e materializa-se através de atributos como instituições, cultura, valores e políticas (Nye, 2004, p. 8) que são centrais para a diplomacia pública (Nye, 2019, p. 11; Melissen, 2005, p. 4).

O termo soft power foi cunhado por Nye na obra "Bound to Lead: The Changing Nature of American Power", que analisa a posição geopolítica dos EUA no sistema internacional contemporâneo (1991, p. XVII). A obra discorre sobre o fortalecimento dos EUA, em virtude da tripla dimensão do poder: militar, económico e soft power (1991, pp. XI, 5, 22). Após definir o poder como "the ability to achieve one's purposes or goals" (1991, p. 3), Nye contextualiza o soft power como o estilo de poder atrativo, composto principalmente por fatores intangíveis 
(1991, pp. XVI, 29-31), sendo não apenas um contraponto ao hard power, mas tão importante como este (1991, pp. 3, 175, 182). O autor afirma que "a country may achieve the outcomes it prefers in world politics because other countries want to follow it or have agreed to a system that produces such effects" (Nye, 1991, p. 31). A natureza mutável do poder confere legitimidade ao soft power, levando à redução de eventuais resistências internacionais (Nye, 1991, p. 32).

Posteriormente, na obra Soft Power: the means to success in world politics, Nye conceituaria o soft power como "ability to get what you want to do with through attraction rather than coercion or payments... ability to shape the preferences of others...[a] co-optive power" (2004, pp. X, 5, 7). Adicionalmente, descreveu as principais fontes de soft power: (1) cultura, principalmente relacionada com elementos internacionalmente atrativos, fonte conhecida na China por soft power cultural (wénhuà ruăn shíli文化软实力); (2) valores, essencialmente quando há identidade entre a imagem internacionalmente projetada e a imagem percebida no âmbito doméstico; e [3] políticas dotadas de autoridade moral (2004, pp. 11-15). O autor adverte que o soft power é contextual. Por exemplo, produções audiovisuais exaltando liberdade e empoderamento feminino, frequentemente apreciadas na América Latina e Índia (Powers \& Samuel-Azran, 2015, pp. 3-4) podem minar o soft power em países como a Arábia Saudita (Nye, 2004, pp. 12, 16, 52). Outrossim, Nye destaca duas variáveis principais do soft power: influência e atração (2004, p. 8).

A principal limitação do soft power é o fato de que, especialmente em democracias, ele não está sob o controle absoluto do Estado, tal como o hard power (2004, pp. 15, 17). Por exemplo, grande parte da atração dos EUA não foi produzida pelo governo americano, mas sim pela sociedade civil, nomeadamente Hollywood. O caso da China é diferente, pois grande parte do acervo de soft power está sob o domínio do governo chinês. Contudo, a peculiaridade é paradoxal, pois emana suspeitas sobre as soft actions da China na dimensão internacional (Nye, 2019, p. 16).

De qualquer modo, desde 1993, quando a versão traduzida da primeira obra de Nye foi publicada na China, debates entusiasmados sobre o soft power vêm sendo promovidos no país (Ramsley, 2020, p. 286). Académicos, políticos e jornalistas incorporaram rapidamente o conceito (Wang Y., 2008, p. 258), levando à constatação de que talvez o soft power não tenha sido tão debatido e aplicado em qualquer outro local do mundo como o foi na China (Wang J., 2011, p. 1).

Posteriomente, Nye formulou o conceito de smart power, obtido pelo uso estratégico do soft e do hard power (poder militar), promovendo a potencialização do poder político (2004, p. 32). Idealmente, o soft power carece de complementos de natureza não soft (Nye, 2019, p. 8). Na mesma linha, Snow destaca 
que as soft actions funcionam melhor quando combinadas com "more forceful and threatening forms of compliance and persuasion" (2020, p. 4). Com efeito, o argumento central desta investigação coloca o sharp power como o complemento ao soft power na diplomacia pública chinesa, operando tanto no nível interno quanto externo, tendo sido decisivo para o êxito no enfrentamento da pandemia de COVID-19.

\subsection{Sharp power}

O sharp power, divulgado na China com o significado de poder afiado (ruì shílì 銳實力), é o estilo de ação que privilegia o viés autoritário em detrimento da atração e influência inerentes ao soft power (Walker \& Ludwig, 2017a, p. 6; Nye, 2019, p. 16). Ou seja, o sharp power coloca-se como um contraponto ao soft power, podendo ser utilizado isoladamente na diplomacia pública ou como complemento ao estilo soft power.

Embora já estudado em relação a outros países (Biersteker, 2020; Walker, 2018, p. 16), tal estilo e ou modelo surge normalmente associado à China e à Rússia no desenvolvimento de ações visando o domínio mundial (Walker, Kalathil, \& Ludwig, 2020, p. 125, Ash, 2019; Bandurski, 2019; Cole, 2018). Do outro lado, autores e autoridades asiáticas classificam tais afirmações como narrativas ocidentais infundadas (Peng, 2019; Si, 2018; Jun, 2017; Chou, 2019). Por exemplo, Wang Guoqing, spokesperson do $13 .^{\circ}$ Comité Nacional da Conferência Consultiva Política do Povo Chinês, afirmou que «Accusing China of showing "sharp power" by some western people is full of hype and bias [...] western countries demonstrate their "soft power" or "smart power," while claiming the same demonstration from China is "sharp power"》 (citado por Yamei, 2018, para. 2). Entre os não ocidentais, há também quem declare que as argumentações em torno do sharp power são o reconhecimento expresso de que os EUA temem o poder geopolítico da China no mundo contemporâneo (Ma, 2019). Já se afirmou que a pujança económica e cultural que dá ritmo à marcha acelerada da China constitui a expressão máxima do poder afiado (Cui, 2017). Nesta linha, a BRI é apontada como exemplo do estilo sharp power da China (Meng, 2019) podendo, a esse propósito e nesse contexto, invocar-se o avanço da Polar Silk Road no Ártico como um exemplo muito concreto da aplicação daquele (Balão, 2018). Na verdade, o fato é que as discussões sobre a natureza e a legitimidade do sharp power seguem em processo de construção.

Há especialistas que estudam o sharp power a partir do soft power (Bouvin, 2019), outros o enquadram como uma forma de hard power (Nye, 2019, p. 17). Também há os que o considerem uma ferramenta do smart power (Buchanan, 2018). Entretanto, quando conceberam o termo em 2017, Walker e Ludwig ti- 
nham em mente um estilo de poder com efeitos mais negativos que positivos, definindo-o como aquele que "pierces, penetrates, or perforates the political and information environments in the target countries" (Walker \& Ludwig, 2017b, p. 6). Nomeadamente, o sharp power tem sido apontado como meio de domínio geopolítico de que se valem especificamente China e Rússia (Ash, 2019; Bandurski, 2019; Cole, 2018; Walker, Kalathil, \& Ludwig, 2020, p. 125), Irão e Azerbaijão (Walker C., 2018, pp. 15-16). As autoras deste artigo entendem, ao contrário da visão, ideia, definição 'média', 'normalizada', que o sharp power é um estilo e ou modelo de ação susceptível de ser adotado/aplicado por diferentes atores da conjuntura global, não estando/sendo limitado/restrito a países e ou atores específicos.

Segundo os autores que conceberam a ideia, a visão original referente ao conceito, o sharp power concretiza-se através, designadamente, da hostilidade à liberdade de expressão e às liberdades individuais, bem como à promoção da desinformação (Walker \& Ludwig, 2017b, p. 7), sendo normalmente aplicado aos media, academia, elites políticas, setor editorial e think tanks, ocasionando autocensura de formadores de opinião (Nye, 2018). O 'estilo' é revelado em ações como manipulação de opiniões, dissimulação de políticas, supressão de vozes (Walker \& Ludwig, 2017b, p. 9), bullying, pressão, rejeição de vistos, corte de concessões, espionagem (The Economist, 2017), constrição de acesso a informações (Nye, 2018), manipulação de diásporas, interferência em eleições estrangeiras, censura, fake news, diplomacia caviar (corrupção) e controle através das capacidades de inteligência artificial e big data (Walker, 2018, pp. 11-17). Tais ferramentas podem ser categorizadas em duas variáveis de sharp power: imposição e domínio (Santos, 2021b). A imposição abarca atributos como restrição de liberdade de expressão, manipulação, desinformação e coerção. Por seu lado, o domínio engloba atributos como violações legais e restrições às liberdades individuais.

A partir de tais variáveis e atributos é possível constatar que o sharp power não está restrito aos "target countries" como referem Walker e Ludwig (2017b, p. 6). Tal padrão está presente em ações praticadas durante a Guerrra Fria. A Operação Denver do soviético KGB, nos anos 1980, criou a fake news de que o HIV era criação dos Estados Unidos da América (Selvage, 2021). De forma similar, as operações psicológicas (PSYOP) usadas pelos EUA em sincronia com outras ações de diplomacia púbica (Joint Chief of Staff, 2003, p. VI-13) para influenciar emoções e atitudes de nativos e combatentes (Kilbane, 2009, p. 187) explorando suas vulnerabilidades (US Department of the Army, $2003 \mathrm{p}$. $\mathrm{J}-1$ ), suscitam questões éticas susceptíveis de serem consideradas na fronteira com a manipulação (Zelcer, VanPelt, \& Casey, 2018). Mais recentemente, o de- 
bate entre os presidentes da França e do Brasil no verão de 2019 em torno dos incêndios na Amazônia com recurso a informações distorcidas são um exemplo clássico de sharp power (Santos, 2021c, p. 48). Outro caso em referência é a vigilância em massa levada a cabo pelo ator EUA e revelada por Edward Snowden em 2013 (Martino, 2020, p. 27). Da mesma forma, a concessão de apoio brasileiro técnico-agrícola a países da África em troca de apoio e votos para candidaturas à direção de organismos internacionais (Lora, 2022 [forthcoming], pp. 6-7) pode ser, igualmente, caracterizada como sharp power.

$\mathrm{Na}$ verdade, são várias as ações caracterizáveis como sharp power no âmbito da diplomacia pública e que têm sido identificadas como tal por diversos autores sem, no entanto, incluírem uma referência direta àquele termo/conceito. Nye cita táticas para influência internacional como pressão diplomática, manipulação (1991, p. 200) e recompensas obscuras (2004, p. 5), tal como Bjola e Murray identificam as cyber-intelligence operations (2016, p. 202), enquanto Cull menciona ações como protestos, boicotes desportivos, manipulação de documentos e suborno de jornalistas no leque da advocacia (2019, p. 55). De um modo geral, o termo é usado para se referir a uma abordagem de relações internacionais (Walker C., 2018, p. 11), que envolve posturas contrárias a padrões éticos.

No que se refere ao sharp power chinês, ele é especificamente identificado, também, através de nomenclaturas como "China Threat 3.0" (Koetse, 2018; Mandip, 2018, p. 9) ou "foreign political influence operations" (FPIO) (Cole, 2018), demonstrando a visão negativa estabelecida a seu respeito. Contudo, a pandemia de COVID-19 vem demonstrando que o sharp power pode ser um estilo não apenas útil, mas necessário ao acervo diplomático do Estado (Santos, 2020a, p. 90), sendo tão importante quanto o soft e o hard power. Assim como o soft power pode ser usado para fins negativos, nefastos (Nye, 2019, p. 17), também pode gerar resultados positivos. Apesar de ser possível distinguir o sharp power da diplomacia pública em virtude dos meios de implementação (Taehwan, 2018), o primeiro tem sido estudado no domínio da segunda (Melissen \& Wang, 2019, p. 4) podendo, assim, servir como complemento eficiente ao soft power (Santos, 2019; Santos, 2020a), como argumenta esta investigação.

Por fim, cumpre reforçar que é entendimento das autoras deste artigo que o sharp power é um fenómeno cuja prática e ou manifestação da sua presença é susceptível de ser passível de identificação à escala global, pelo que não constitui um padrão restrito a países específicos. Por isso, pode ser definido como o estilo de ação, de atuação que, ‘adicionado' ao processo de diplomacia pública se revela em ações que podem ser de imposição e ou domínio, à totalidade ou parte do processo de execução de ações que podem ter sido iniciadas no ambiente doméstico (esfera interna), mas que foram subsequentemente, 
no âmbito e através do processo de conversão de Poder, traduzidas em resultados de diplomacia pública (portanto, projetados para o ambiente externo, considerado simultaneamente numa perspetiva multinível e multidimensão). Podem, ainda, ter sido operacionalizadas diretamente na esfera internacional, revelando como atributo as violações legais e restrições às liberdades individuais no caso do domínio; e restrições à liberdade de expressão, manipulação, desinformação e coerção no âmbito da imposição.

\section{Matriz analítica}

O enquadramento analítico que pavimenta a exploração empírica da investigação sustenta-se na revisão bibliográfica. Da diplomacia pública, foram extraídas as ferramentas chinesas detalhadas na Tabela 2. Em relação ao soft power e ao sharp power, foram isoladas as variáveis e atributos de ambos os estilos e ou modelos de ação. Assim, a relação de tais elementos encontra-se sumarizada na matriz demonstrada na Figura 2. A coleta e análise de dados para composição do estudo de caso foi conduzida com as lentes da matriz analítica, de acordo com o research design detalhado na próxima seção.

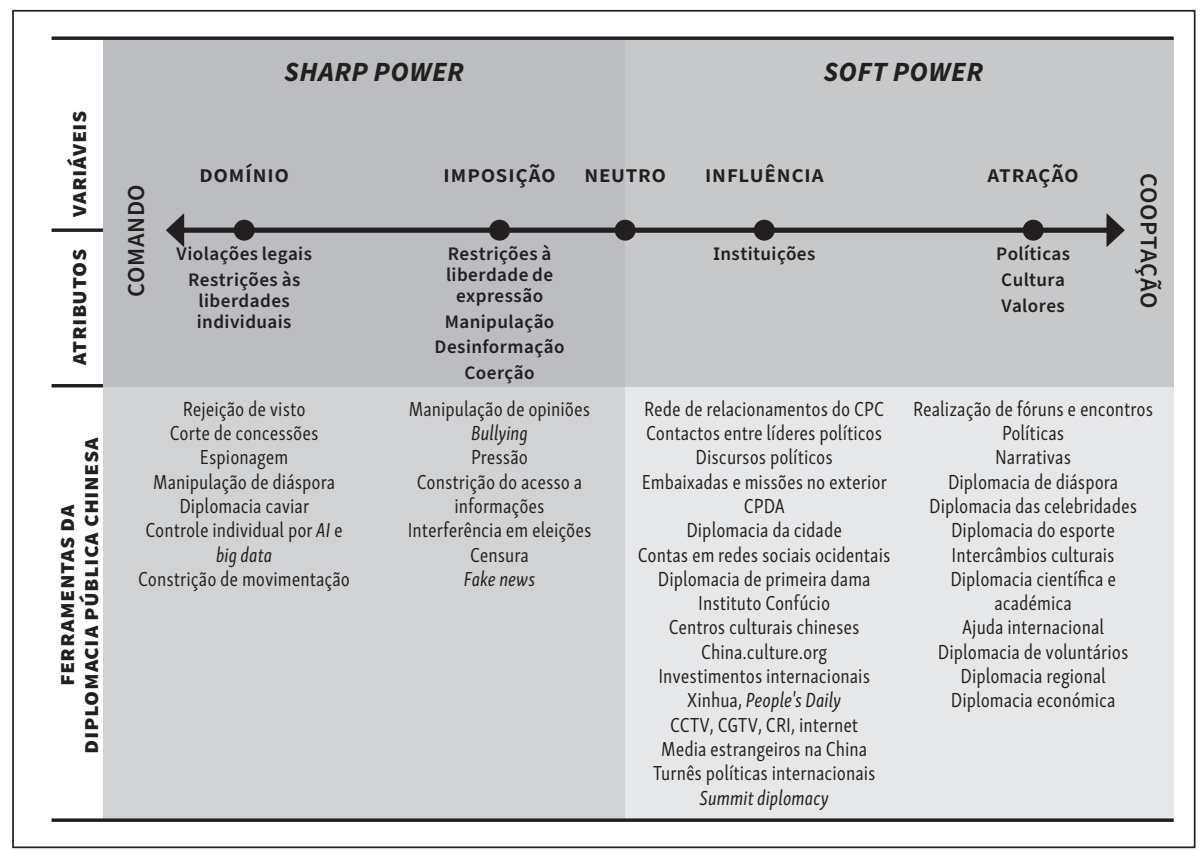

FIGURA 2

Matriz dos estilos sharp power e soft power na diplomacia pública chinesa

Fonte: elaborado pelas autoras, com inspiração em Santos (2019, p. 82). 


\section{Research design}

Para obter a resposta à questão de pesquisa do tipo "como", que pressupõe compreensão detalhada, sem pretensão de generalização, é adotado o estudo de caso como método (Yin, 2018). A análise concentra-se nas ações chinesas realizadas no contexto de controle da pandemia de COVID-19 no primeiro quadrimestre de 2020, período de pico e controle da emergência sanitária no país.

Fontes primárias e secundárias alimentam a coleta de dados, ampliando a consistência do estudo. As fontes primárias são: (1) o white paper emitido pelo SCIO em junho de 2020 (SCIO, 2020) e (2) o relatório de trabalho do governo apresentado pelo premier em maio de 2020 no $13 .{ }^{\circ}$ Congresso Nacional do Povo (Dì shisān jiè quánguó rénmín dàibiǎo dàhuì 第十三届全国人民代表大 会) (Keqiang, 2020). As secundárias são: (1) o relatório do China Watch Institute (CWI et al., 2020); e o (2) relatório da WHO (2020a). O alcance global e a exposição internacional das fontes secundárias através da mediated diplomacy evidenciam o carácter de diplomacia pública dos factos veiculados nas fontes primárias.

A construção do caso operou-se em duas fases: coleta de dados primários e confirmação de consistência, ambas alicerçadas na matriz analítica (Figura 1). No primeiro estágio, foram identificadas ferramentas chinesas de diplomacia pública durante o enfrentamento da pandemia a partir de fontes primárias. Em seguida, foi identificado o atributo da respetiva ação e, portanto, a respetiva variável de soft ou sharp power. Adotou-se, assim a técnica de coding para a coleta e análise dos dados (Krippendorff, 2004, pp. 99-101), organizando-os em working sheets. Na segunda etapa, tais informações foram conferidas nas fontes secundárias. $O$ estudo de caso foi composto a partir de informações selecionadas das working sheets (Anexo), referindo-se a conteúdo observado nas fontes primárias e reproduzido em fontes secundárias.

\section{Estudo de caso: A COVID-19 na China}

Os primeiros casos de pneumonia de etiologia desconhecida foram reportados à WHO em 31 de dezembro de 2019. As ocorrências foram identificadas no Hospital Wuhan Jinyintan (Wǔhàn shì jīnyíntán yīyuàn 武汉市金银潭医院)em Wuhan, província de Hubei, região central da China (WHO, 2020b). Com 11 milhões de habitantes, a cidade foi o primeiro epicentro da COVID-19.

Após a sociedade internacional perceber a ameaça global, assistiu-se a uma rápida sucessão de factos e os números de ocorrências acelerou em janeiro de 2020 (WHO, 2020a). No dia três, 44 casos foram confirmados em Wuhan. O compartilhar, à escala mundial, da sequência genética do vírus ocorreu na primeira quinzena do mês, altura em que foi igualmente revelado que o 
agente causal estaria associado ao Mercado de Venda por Atacado de Frutos do Mar de Huanan (Wǔhàn Huánán hăixiān pīfā shìchăng 武汉华南海鲜批发市 场). No dia 11, as autoridades chinesas confirmaram a primeira fatalidade em Wuhan. Dois dias depois, foram reportados os primeiros casos internacionais na Tailândia, Japão e Coreia do Sul. A WHO declarou a emergência global de saúde pública em 30 de janeiro e a pandemia em 11 de março.

O controle da COVID-19 na China foi reconhecido pela WHO em março (Ghebreyesus, 2020). Por outro lado, a doença espalhava-se rapidamente pelo globo terrestre. Desde a eclosão do surto e até 6 de julho de 2021, mais de 180 milhões de pessoas foram contaminadas ao redor do mundo, havendo perto de 4 milhões de vítimas fatais (WHO, 2021a). No mesmo período, a China contabilizou 119.036 casos de contaminação e 5.554 fatalidades, enquanto a Europa apresentou respetivamente os totais de 56.235.850 e 1.189.019 e os Estados Unidos, 33.392.406 e 600.457 (WHO, 2021b). É verdade que há críticas e desconfiança sobre os números divulgados pela China e ratificados pela WHO (He, Li, Dehner, \& Dunn, 2020; Campbell \& Gunia, 2020). Contudo, tais juízos parecem remanescer tendo por base inferências não comprovadas e ou não conferidas, confirmadas por pares (He, Li, Dehner, \& Dunn, 2020). De qualquer modo, caso os números chineses fossem 150\% maiores (Ma, Lew, \& Jeong-Hoo, 2020) ou até 400\% superiores (Tsang, Wu, Lin, et al., 2020) aos reportados publicamente, ainda seriam significativamente inferiores aos da Europa e dos EUA. Assim, além de ser reconhecido internacionalmente como um sucesso, o desempenho da China no controle da pandemia (The Lancet, 2020; Castañón \& Esomonu, 2020; AlTakarli, 2020; Cyranoski, 2020; Ghebreyesus, 2020) também é ratificado pelos números oficiais.

De facto, perante a gravidade da situação, em janeiro de 2020 o presidente Xi Jinping emitiu instruções para que autoridades e departamentos de todos os níveis de governo e do partido tornassem prioridade absoluta a segurança e a vida das pessoas, com planos completos para contenção efetiva da epidemia (Wang K., 2020). Na ocasião, foi ainda determinada a adoção de medidas para manutenção da estabilidade geral da sociedade e a comunicação proativa com a WHO e outras nações (Wang K., 2020). Seguindo as diretrizes de Xi Jinping, criou-se o "grupo de liderança da resposta à COVID-19" (Zhōngyāng yìngduì xīnxíng guānzhuàng bìngdú gănrăn fèiyán yìqíng gōngzuò lǐngdăo xiăozǔ 中央应 对新型冠状病毒感染肺炎疫情工作领导小组), presidido pelo premier (Xinhua, 2020).

O plano de enfrentamento envolveu ações em três frentes: saúde e pesquisa, monitoramento social e governança pública (Santos, 2020a), conforme exemplos apontados resumidamente na Tabela 3. Tais ações foram desenvol- 
vidas em ambiente doméstico com posterior conversão em resultados de diplomacia pública projetados à escala global ou desenvolvidas diretamente no plano internacional, especialmente através de intercâmbios de informações.

TABELA 3

Tabela de categorização das medidas de combate à COVID-19

\begin{tabular}{|c|c|}
\hline FRENTE & FERRAMENTAS \\
\hline $\begin{array}{l}\text { Saúde e } \\
\text { pesquisa }\end{array}$ & $\begin{array}{l}\text { Protocolos de diagnóstico e tratamento, assistência psicológica e social, política } \\
\text { de testagem, preparação do sistema de saúde, regulamentos para funeral e } \\
\text { sepultamento, obrigatoriedade de uso de máscaras, proteção dos profissionais de } \\
\text { saúde, pesquisas científicas. }\end{array}$ \\
\hline $\begin{array}{l}\text { Monitoramento } \\
\text { social }\end{array}$ & $\begin{array}{l}\text { Políticas de isolamento e quarentena, fechamento total ou parcial de fronteiras, } \\
\text { testagem em aeroportos, fronteiras e pelo país, suspensão de voos internacionais, } \\
\text { restrições de locomoção doméstica, restrições de visto, toque de recolher, } \\
\text { vigilância e monitoramento, inclusive tecnológico, regras de distanciamento } \\
\text { social e confinamento (lockdown), proibição de reuniões públicas, fechamento de } \\
\text { escolas, serviços públicos e empresas, políticas prisionais restritivas. }\end{array}$ \\
\hline $\begin{array}{l}\text { Governança } \\
\text { pública }\end{array}$ & $\begin{array}{l}\text { Medidas económicas, estruturas de emergência, políticas de importação e } \\
\text { exportação, declaração de estado de emergência, medidas militares específicas, } \\
\text { campanhas educativas e de sensibilização, construção acelerada de hospitais de } \\
\text { campanha. }\end{array}$ \\
\hline
\end{tabular}

Fonte: quadro elaborado pelas autoras com base em WHO (2020a) e CWI et al. (2020).

Sob a perspetiva da diplomacia pública que aqui é considerada, apresentada e discutida, ações domésticas ganham feição internacional diante do carácter global da COVID-19. Exemplificativamente, medidas domésticas de saúde e pesquisa foram rapidamente compartilhadas com a comunidade internacional e a WHO. É o caso da sequência genómico do novo vírus (Anexo, QA, 1)[3], dos protocolos de diagnóstico, testagem, controle da transmissão, tratamento e das diretrizes sobre proteção dos profissionais da saúde (Anexo, QA, 2, 4, 5, 7, 9), bem como das investigações epidemiológicas (Anexo, QA, 3) e dos estudos emergenciais sobre terapêutica da doença (Anexo, QA, 10). Paralelamente, ainda no campo da saúde e pesquisa, a China desenvolveu outras ações com carácter deliberadamente internacional, nomeadamente as

3. Neste padrão de referenciação a fonte é o Anexo. O código Q indica o quadro (QA [saúde e pesquisa], QB [monitoramento social], QC [governança pública]) e o número após o código Q indica a linha do respetivo quadro em que a informação está identificada. 
pesquisas científicas em coautoria com especialistas internacionais (Anexo, QA, 6, 11) e a promoção de conferências virtuais (Anexo, QA, 8). Todas as intervenções estão no âmbito da diplomacia científica, ferramenta da variável influência do estilo soft power.

A 'frente' da governança pública, também exigiu ferramentas da variável influência presentes no estilo soft power. Tanto o presidente quanto o premier desenharam e definiram políticas e narrativas em torno das epígrafes "futuro compartilhado para a humanidade", "vidas humanas em primeiro lugar" e "wartime pandemic command system" (Anexo, QC, 1, 2). Destacaram-se, ainda, ações como o grupo de resposta liderado pelo premier (Anexo, QC, 3), o adiamento do feriado de primavera (Anexo, QC, 4), as campanhas de prevenção (Anexo, QC, 5), as medidas para manutenção da estabilidade económica (Anexo, QC, 18), bem como os protocolos para desinfecção e ventilação de locais públicos (Anexo, QC, 22), assim como para flexibilização das medidas restritivas (Anexo, QC, 20), além da 'perseguição' de dados estatísticos fidedignos quanto à COVID-19 (Anexo, QC, 13). Ações alicerçadas nos media estrangeiros instalados na China também se fizeram presentes na governança pública, ampliando o soft power na variável influência. Trata-se das entrevistas coletivas de imprensa com o SCIO (Anexo, QC, 11) e os press releases para imprensa internacional e redes sociais, visando (expressamente) influenciar a opinião pública (Anexo, QC, 14).

Adicionalmente, a variável atração do soft power apresentou-se na governança pública em medidas como a plataforma digital de dados sobre a doença (Anexo, QC, 13), os incentivos para desenvolvimento do e-commerce e tecnologias contactless (Anexo, QC, 17), a organização de voluntários comunitários (Anexo, QC, 21), e o relacionamento permanentemente mantido com a WHO, visando a ampliação da cooperação internacional (Anexo, QC, 19).

Por outro lado, o estilo sharp power também se mostrou presente na esfera da governança pública. Nesse caso, a pressão foi o atributo mais utilizado. São exemplos: a mobilização realizada em toda a China para assegurar as necessárias equipas médicas (Anexo, QC, 15) e suprimentos hospitalares na província de Hubei (Anexo, QC, 6, 10, 16), bem como para assegurar o abastecimento de commodities (Anexo, QC, 8). Há ainda significativos exemplares do atributo pressão do estilo sharp power na esfera da governança pública com benefícios diretos e imediatos à sociedade chinesa, como a manutenção de preços decorrente da gestão sobre fornecedores (Anexo, QC, 9) e a construção de hospitais com mais de 1000 leitos em apenas 10 dias (Anexo, QC, 7). Este, em particular, é um dos exemplos que melhor demonstra como as medidas chinesas adoptadas inicial e originalmente na esfera doméstica ganharam notoriedade em todo o mundo, provocando admiração pela eficiência e rapidez de resposta do 
país (Wang, Zhu, \& Umlaut, 2020) - assim como replicação por parte de muitos Estados à escala mundial -, muito embora cada uma de tais medidas internas tenham ganho notoriedade internacional através da diplomacia mediada pelos media internacionais.

Por fim, a vertente monitoramento social destaca-se pela preponderância de ações revestidas de sharp power. Muito embora se tenha assistido ao reconhecimento internacional do controle da pandemia na China, muitas das medidas ali adotadas foram consideradas "brutais" em face do carácter considerado autoritário - de que as mesmas se revestiram (Graham-Harrison \& Kuo, 2020). Esta é a situação específica de ações como os check points para medição de temperatura e testagem obrigatórios, inclusive para estrangeiros (Anexo, QB, 1, 13), a fiscalização do uso de máscaras nas ruas (Anexo, QB, 10), a restrição de mobilidade (Anexo, QB, 3), o confinamento e a quarentena obrigatórios (Anexo, QB, 2, 5, 7), o isolamento e controle de pessoas do grupo de risco, pessoas contaminadas e contatos próximos (Anexo, QB, 5, 9), bem como a proibição de reuniões (Anexo, QB, 6). A proibição de funcionamento de atividades de lazer e consumo, nomeadamente academias, cinemas e shopping centers (Anexo, QC, 8), das escolas (Anexo, QC, 12) e do trabalho presencial (Anexo, QC, 11) também configuram o sharp power entre as medidas de monitoramento social. Significativamente, as medidas domésticas de monitoramento emergem de políticas como fonte de diplomacia pública (Figura 1), tendo sido viabilizadas através de pressão, constrição de movimentação, espionagem e censura (Apêndice, QB). Entretanto, conjugadas estrategicamente com o soft power, através de intercâmbios internacionais e international broadcasting, tais medidas geraram preferred outcomes de diplomacia pública.

Graves crises, essencialmente as que ameaçam a vida humana, demandam decisões e ações ágeis e efetivas que nem sempre são suportadas apenas pelo soft power. Assim, o sharp power revela-se um estilo de ação necessário em cenários emergenciais. Tal como a China, outros países inspirados pelo bem sucedido controle da pandemia, também utilizaram medidas de sharp power, com aprovação global das medidas de controle da pandemia pela população (Wu, Shi, Wilkes, et al., 2021). A Coreia do Sul, situada entre os 25 países mais democráticos do mundo (The Economist, 2021) é um exemplar de tal constatação (Zastrow, 2020). Portanto, não é difícil concluir que, assim como o soft power, que pode servir para objetivos nefastos (Nye, 2019, p. 17), o estilo sharp power pode gerar resultados finais positivos.

$\mathrm{O}$ estudo de caso e o entendimento detalhado do enfrentamento da COVID-19 pela China sinalizam que o país orquestrou com maestria os estilos soft e sharp power na luta contra a COVID-19. Assim, o país mais populoso do 
mundo obteve êxito no controle da pandemia num período temporal inferior a três meses, utilizando amplamente o instrumental da diplomacia pública. Apesar das críticas, o facto é que a China foi reconhecida pela WHO em virtude do seu papel "in protecting the global community and creating a stronger first line of defense against international spread" (WHO, 2020a, p. 17).

O estudo detalhado das informações de fontes primárias e secundárias realizado nesta investigação levou à constatação de que a China adotou um equilibrado e assertivo acervo de ferramentas de diplomacia pública composto maioritariamente pelos atributos políticas e valores da variável "atração" do soft power e o atributo coerção da variável "imposição" do sharp power. Com efeito, é possível afirmar que a performance global da China durante a pandemia de COVID-19 foi eficaz e ajustada ao desafio colocado, constituindo um clássico exemplo da diplomacia pública chinesa, que tem como marca singular a articulação entre o soft e o sharp power, mas com uma importante nuance: susceptível de utilização quer na esfera interna, quer externa - desafiando de forma clara e inequívoca as assumpções centrais da visão 'tradicional' sobre sharp power e diplomacia pública.

\section{Conclusão}

A China foi o primeiro epicentro da pandemia de COVID-19 que, até 6 de julho de 2021 havia contaminado perto de 180 milhões de pessoas ao redor do mundo, deixando um rasto de aproximadamente 4 milhões de vítimas fatais. Diante do desafio, a diretriz do presidente Xi Jinping determinava a prioritização da segurança e vida das pessoas. Nesse diapasão, sob a liderança do premier Li Keqiang foi criado o grupo de liderança da resposta à COVID-19, o qual coordenou o plano de enfrentamento da emergência sanitária. Em virtude do caráter global da ameaça, além das medidas realizadas no âmbito internacional, como a partilha dos conhecimentos científicos sobre o vírus, controlo e combate à pandemia, e outras questões associadas, também as ações e políticas domésticas foram projetadas para a dimensão internacional, inspirando os países que viriam a enfrentar posteriormente o mesmo desafio. Com o reconhecimento internacional do sucesso no controle da pandemia, a China tornou-se um case de diplomacia pública.

Esta investigação foi desenvolvida com o objetivo de compreender como a China articulou de forma bem sucedida os estilos de soft power e sharp power no âmbito da diplomacia pública durante o combate à pandemia de COVID-19. Para tanto, após a contextualização da China, a revisão bibliográfica promoveu a operacionalização dos conceitos de diplomacia pública, com foco na diplomacia pública chinesa, soft power e sharp power. A "Matriz dos estilos sharp 
power e soft power na diplomacia pública da chinesa” é resultado desta etapa e também um importante outcome da investigação, pois pode subsidiar pesquisas e desenvolvimentos futuros relacionados com a diplomacia pública da China.

A análise empírica iluminada pela matriz revelou que as ações chinesas ocorreram em três frentes principais: (1) saúde e pesquisa, (2) monitoramento social e (3) governança pública. O primeiro grupo traduziu-se em ações de diplomacia científica, permeadas pelo soft power. Por sua vez, ações do segundo grupo (monitoramento social), com foco predominantemente doméstico, demandaram o estilo sharp power, através de ferramentas como constrição de liberdades, pressão e rastreamento tecnológico de cidadãos. Por fim, o terceiro grupo, também predominantemente voltado ao ambiente interno, exigiu o uso combinado de soft e sharp power. Com efeito, o perceptível sucesso da China no controle da pandemia serviu da inspiração e foram adotados em vários Estados do mundo, inclusive naqueles considerados democráticos.

Com efeito, a análise empírica permitiu concluir que a China adotou uma ampla gama de ferramentas de diplomacia pública durante o enfrentamento da pandemia de COVID-19 combinando os dois estilos. O soft power foi demandado essencialmente em ações realizadas primariamente na dimensão internacional e o sharp power preponderantemente adotado em medidas e políticas domésticas que foram convertidas em influência internacional, principalmente nas frentes de monitoramento social e governança pública, projetando uma imagem particularmente favorável à China no que se refere a capacidade e credibilidade. Na verdade, a aplicação situacional do soft e do sharp power combinando as potencialidades de cada um de acordo com a situação apresentada, conduziu a China ao rápido controle da pandemia com reconhecimento internacional. Destarte, a investigação com as lentes da matriz analítica permitiu responder à questão de pesquisa, evidenciando ainda que o estilo sharp power tem seu lado positivo e até mesmo necessário, especialmente em cenários de crise como é o caso da pandemia de COVID-19.

Futuros desenvolvimentos a partir dessa investigação, podem contemplar a utilização da matriz analítica para estudo empírico de outras situações envolvendo a diplomacia pública chinesa. Além disso, pode ser empreendida a análise do sharp power em países com desempenho não satisfatório no combate à pandemia. $\mathrm{O}$ maior acervo de estudos nesta área permitirá futuras conclusões sobre se o sharp power pode ser incluído como elemento útil e necessário ao acervo diplomático. 


\section{Referências}

Alon, I., Farrell, M. \& Li, S. (2020). Regime type and COVID-19 response. FIIB Review, 1-9. doi: 10.1177/2319714520928884.

AlTakarli, N. S. (2020). China's Response to the COVID-19 Outbreak: A Model for Epidemic Preparedness and Management. Dubai Medical Journal, 3, 44-49. doi: $10.1159 / 000508448$.

Ang, Y. Y. (2018). Autocracy with Chinese characteristics. Foreign Affairs, 97, 3, 39-46.

Arceneaux, P. \& Powers. S. (2020). International broadcasting. In N. Snow \& N. Cull (Eds.), Routledge handbook of public diplomacy $2^{\text {nd }}$ ed. New York: Routledge.

Ash, T. (2019, mai., 9). The rise of 'sharp power lending'. Financial Times. Recuperado de https://www.ft.com/content/54710334-7197-11e9-bbfb-5c68069fbd15. [Acesso em 31 jun. 2020].

Balão, S. M. R. (2014). A Matriz do Poder: uma visão analítica da globalização e da anti-globalização no mundo contemporâneo (2a ed.). Lisboa: MGI.

Balão, S. M. R. (2018). A Polar Silk Road e a (Geo)Estratégia da China no Século XXI. In A. S. Lara (Coord.), Estado, Ordem International e Novas Ameaças (pp. 101-138). Lisboa: MGI.

Balzer, H. (2003, jul.). Managed pluralism - Vladimir Putin's emerging regime. Post-Soviet Affairs, 19(3), 189-227.

Bandurski, D. (2019). Documenting China's Influence. In I. Franceschini \& N. Loubere (Eds.), Dog Days: made in China yearbook 2018. Canberra: ANU Press.

Biersteker, T. (2020). The potential of Europe's sharp and soft power. Global Policy, 11, 3, 384-387.

Bjola, C. \& Murray, S. (2016). Secret diplomacy: Concepts, contexts and cases. Abingdon: Routledge.

Bouvin. M. (2019, jun., 7). The Hard Edge of China's Soft Power. Global Security Review. Recuperado de https://globalsecurityreview.com/hard-edge-china-soft-power/ [Acesso em 13 ago. 2020].

Bradshaw, W. J., Alley, E. C., Huggins, J. H. et al. (2021). Bidirectional contact tracing could dramatically improve COVID-19 control. Nature Communications 12, 232. doi: 10.1038/s41467-020-20325-7.

Buchanan, P. (2018, out., 24). Confronting Sharp Power. 36th-parallel Geopolitics and Strategic Assessments. Recuperado de https://36th-parallel.com/2018/10/24/confronting-sharp-power/ [Acesso em 10 jun. 2020].

Campbell, C. \& Gunia, A. (2020, abr., 1). China says it's beating coronavirus: but can we believe its numbers? Time. Recuperado de https://time.com/5813628/china-coronavirus-statistics-wuhan/ [Acesso em 25 ago. 2020].

Campbell, K. M., \& Doshi, R. (2020, mar., 18). The coronavirus could reshape global order. Foreign Affairs. Recuperado de https://www.foreignaffairs.com/articles/ china/2020-03-18/coronavirus-could-reshape-global-order [Acesso em 31 mai. 2020].

Castañón, L. \& Esomonu, E. (2020, jun., 29). Researchers examine why the U.S. hasn't had the same success as China in slowing the spread of the coronavirus. Medi- 
cal Xpress. Recuperado de https://medicalxpress.com/news/2020-06-hasnt-success-china-coronavirus.html [Acesso em 25 jul. 2020].

Changhe, S. (2010). Understanding Chinese diplomatic transformation: a multi-actors' perspective. The Hague Journal of Diplomacy, 5,4, 313-329.

Chen, C. C. \& Colapinto C. (2010). China Radio International in the digital age: propagating China on the global scenario. China Media Journal, 9, 16, 1-15.

Chen, N. (2011). The evolving Chinese government spokesperson system. In J. Wang, Soft power in China: public diplomacy through communication. New York: Palgrave.

Cheng, Z., Golan, G. J. \& Kiousis, S. (2015). The second-level agenda-building function of the Xinhua News Agency. Journalism Practice. doi:10.1080/17512786.2015.1063079

China Watch Institute (CWI) et al. (2020, abr., 21). China's fight against COVID-19. China Daily. Recuperado de http://www.chinadaily.com.cn/pdf/2020/Chinas. Fight.Against.COVID-19-0420-final-2.pdf [Acesso em 2 ago. 2020].

Chou, Z. (2019, mai. 22) “锐实力”是对中国的歪曲解读. “Ruì shílì" shì duì zhōngguó de wāiqū jiědú. [O "Sharp power” é uma interpretação distorcida da China]. 求是网Qiú shì wăng. Recuperado de http://www.qstheory.cn/dukan/hqwg/ 2019-05/22/c_1124523258.htm [Acesso em 20 ago. 2020].

Cole, M. (2018). The hard edge of sharp power: understanding China's influence operations abroad. Ottawa: Macdonald-Laurier Institute.

Communist Party of China (CPC) (Zhōngguó Gòngchăndăng 中国共产党). (2017). Constitution of the Communist Party of China. Recuperado de http://www.china.org. cn/20171105-001.pdf [Acesso em 5 abr. 2020].

Confúcio. (2019). Os Anacletos (C. Chang, Trad.). Porto Alegre: LP\&M Editores. [Arquivo Kindle].

Cooper, K-L. (2020, jan., 24). China coronavirus: the lessons learned from the Sars outbreak. BBC News. Recuperado de https://www.bbc.com/news/world-asia-china-51221394 [Acesso em 20 ago. 2020].

Costa, C. M. (2020). The words of the belt and road initiative: a Chinese discourse for the world? In F. J. B. S. Leandro \& P. A. B. Duarte, The Belt and Road Initiative: an old archetype of a new development model. Singapore: Palgrave.

Cui, W. (2017, dez., 22). 复兴路上, 中国软实力“锐”些又何妨Fùxīng lùshàng, zhōngguó ruăn shílì “ruì" xiē yòu héfáng. 新华网Xīnhuá wăng [Xinhua]. Recuperado de http://www.xinhuanet.com/2017-12/22/c_1122150076.htm [Acesso em 20 ago. 2020].

Cull, N. (2019). Public diplomacy: foundations for global engagement in the digital age. Cambridge: Polity.

Cull, N. (2020). Public diplomacy before Gullion: the evolution of a phrase. In N. Snow $\&$ N. Cull, (Eds.), Routledge Handbook of public diplomacy. $2^{\text {nd }}$ ed. New York: Routledge.

Cyranoski, D. (2020). What China's coronavirus response can teach the rest of the world. Nature, 579, 7800, 479-480.

D’Hooghe I. (2014). China's public diplomacy. Leiden: Brill. 
Danziger, J. N. \& Smith, C. A. (2015). Understanding the political world: a comparative introduction to political science. $12^{\text {th }}$ ed. Boston: Pearson.

Duggan, N. (2020). A new Chinese national identity: the role of nationalism in Chinese foreign policy. In L. Zhouxiang, Chinese national identity in the age of globalization. Singapore: Palgrave.

Esarey, A. \& Qiang, X. (2008). Political expression in the Chinese blogosphere: below the radar. Asian Survey, 48, 5, 752-772.

Fazal, T. M. (2020). Health diplomacy in pandemical times. International Organization, 74, 1, E78-E97. doi: 10.1017/So020818320000326.

Fernandes, T. M-S. (2014). Conhecendo o sistema político chinês. Brasília: APEX-Brasil.

Fukuyama, F. (2013). As Origens da Ordem Politica (N. Montingelli Jr., Trad.). Rio de Janeiro: Rocco. [Arquivo Kindle].

Fulda, A., Li, Y., \& Song, Q. (2009, set.). How to gain trust and promote system innovation: strategies of Chinese civil society organisations collaborating with the government (Discussion Paper 52). School of Contemporary Chinese Studies at The University of Nottingham, Nottingham, UK.

Ghebreyesus, T. A. (2020, mar., 9). WHO Director-general's opening remarks at the media briefing on COVID-19 - 9 March 2020. WHO. Recuperado de https://www. who.int/dg/speeches/detail/who-director-general-s-opening-remarks-at-the-media-briefing-on-covid-19---9-march-2020 [Acesso em 31 mar. 2020].

Gilboa, E. (2008). Searching for a theory of public diplomacy. Annals AAPSS 616: 55-77.

Gilboa, E. (2015). Public diplomacy. In G. Mazzoleni (Ed.), International encyclopedia of political communication. Hoboken: Wiley.

Glaubitz, J. (1976). Anti-hegemony formulas in Chinese foreign policy. Asia Survey, 16(3), 205-215.

Goff, P. M. (2020). Cultural diplomacy. In N. Snow \& N. Cull (Eds.), Routledge handbook of public diplomacy. $2^{\text {nd }}$ ed. London: Routledge.

Golan, G. J., Manor, I., \& Arcenaux, P. (2019). Mediated public diplomacy redefined: foreign stakeholder engagement via paid, earned, shared, and owned media. American Behavioral Scientist, 63, 12, 1665-1683. doi: 10.1177/0002764219835279.

Graham-Harrison, E., \& Kuo, L. (2020, mar., 19). China's coronavirus lockdown strategy: brutal but effective. The Guardian. Recuperado de https://www.theguardian.com/world/2020/mar/19/chinas-coronavirus-lockdown-strategy-brutal-but-effective [Acesso em 20 jul. 2020].

Haar, B ter. (2017). What makes a country powerful? Clingendael. Recuperado de https://www.clingendael.org/sites/default/files/2017-12/What_makes_a_country_ powerful.pdf [Acesso em 07 jul. 2020].

Hague, R. , Harrop M. \& McCormick, J. (2016). Comparative government and politics: an introduction. $10^{\text {th }}$ ed. Houndmills: Macmillan.

Haixia, Q. (2017). From Comprehensive National Power to soft power: a study of the Chinese scholars's perception of power. The Griffith-Tsinghua 'how China sees the world' (Working Paper Series n. 7). Griffith Asia Institute at Griffith University, Brisbane, Australia. 
Hartig, F. (2012). Cultural diplomacy with Chinese characteristics: the case of Confucius Institutes in Australia. Communication, Politics \& Culturre, 45, pp. 256-276.

Hartig, F. (2016). Chinese public diplomacy: the rise of the Confucius Institute. London: Routledge.

Hartig, F.(2019). Public diplomacy: Internationale PR für Staaten eine Annäherung. Wiesbaden: Springer.

He, M., Li, L., Dehner, L. P. \& Dunn L. F. (2020). Cremation based estimates suggest significant under- and delayed reporting of COVID-19 epidemic data in Wuhan and China. MedRxiv. doi: 10.1101/2020.05.28.20116012.

Hensengerth, O. (2015). Multi-level governance of hydropower in China? The problem of transplanting a western concept into the Chinese governance context. In E. Ongaro (Ed.), Multi-level governance: the missing linkages. Bingley: Emerald.

Hensengerth, O., \& Lu, Y. (2018). Emerging environmental multi-level governance in China? Environmental protests, public participation and local institution-building. Public Policy and Administration, o, o, 1-23.

Hess, S. (2013). Authoritarian Landscapes: popular mobilization and the institutional sources of resilience in nondemocracies. New York: Springer.

Huang, K. (2018). The 'going out' of China Radio International. In D. K. Thussu, H. de Burgh \& A. Shi, China's media go global. Abingdon: Routledge.

Jesus, J. D. de (2014). Diplomacia, In N. C. Mendes \& F. P. Coutinho (Ed.), Enciclopédia das Relações Internacionais. Alfragide: D. Quixote.

Jiechi，Y. (2012, dez., 31). 杨洁簏部长在中国公共外交协会成立大会上的讲话Yángjiéchí bùzhăng zài zhōngguó gōnggòng wàijiāo xiéhuì chénglì dàhuì shàng de jiănghuà [Discurso do Ministro Yang Jiechi na reunião inaugural da Associação de Diplomacia Pública da China]. 外交部 Wàijiāo bù [Ministério das Relações Exteriores]. Recuperado de https://www.fmprc.gov.cn/web/ziliao_674904/ zyjh_674906/t1002005.shtml [Acesso em 30 jul. 2020]

Jing, Y. (2015). The road to collaborative governance in China. In Y. Jing (Ed.), Governing China in the $21^{\text {st }}$ century: the road to collaborative governance in China (pp. 1-20). New York, Palgrave.

Jinping, X. (2013a, mar., 17). 习近平:在十二届全国人大一次会议上的讲话 Xijinping: Zài shièr jiè quánguó réndà yīcì huìyì shàng de jiănghuà [Xi Jinping: Discurso na Primeira Sessão do $12^{\circ}$ Congresso Nacional do Povo]. 中华人民共和国中央人民 政府 Zhōnghuá rénmín gònghéguó zhōngyāng rénmín zhèngfǔ [Governo central da PRC]. Recuperado de http://www.gov.cn/ldhd/2013-03/17/content_2356344. htm [Acesso em 2 ago. 2020].

Jinping, X. (2013b, out., 3). 习近平:中国愿同东盟国家共建21世纪”海上丝绸之路” Xíjìnpíng: Zhōngguó yuàn tóng dōngméng guójiā gòng jiàn 21 shìjì "hăishàng sīchóu zhī lù" [Xi Jinping: a China está disposta a construir a "Rota da Seda Marítima” do século 21 com os países da ASEAN]. 新华网 Xīnhuá wăng [Xinhua]. Recuperado de http://www.xinhuanet.com/world/2013-10/03/c_125482056.htm [Acesso em 2 ago. 2020].

Jinping, X. (2019, abr., 28). 习近平在第二届“一带一路”国际合作高峰论坛记者会上的讲 话 Xíjìnpíng zài dì èr jiè "yīdài yîlù" guójì hézuò gāofēng lùntán jìzhě huì shàng de jiănghuà [Discurso de Xi Jinping na Conferência do $2^{\circ}$ Fórum de Coope- 
ração Internacional para a Iniciativa Cinturão e Rota]. 中国共产党 Zhōngguó Gòngchăndăng [CPC]. Recuperado de http://jhsjk.people.cn/article/31053842?isindex $=1$ [Acesso em 2 ago. 2020].

Jinsong, L. (2020). China's diplomacy to help fight COVID-19: a prime example of building a community with a shared future for mankind. Foreign Affairs Journal of CPIFA, 136, 15-30.

Jintao, H. (2005, set., 16). 胡锦涛:努力建设持久和平、共同繁荣的和谐世界(全文). Hújǐntāo: Nǔlì jiànshè chíjiǔ hépíng, gòngtóng fánróng de héxié shìjiè (quánwén) [Hu Jintao: Esforce-se para construir um mundo harmonioso de paz duradoura e prosperidade comum (texto completo)]. Recuperado de http://www.china. com.cn/zhuanti2005/txt/2005-09/16/content_5971778.htm [Acesso em 30 jul. 2020].

Jintao, H. (2007, out., 15). 高举中国特色社会主义伟大旗帜 为夺取全面建设小康社会 新胜利而奋斗Gāojǔ zhōngguó tèsè shèhuì zhǔyì wěidà qízhì wèi duóqǔ quánmiàn jiànshè xiăokāng shèhuì xīn shènglì ér fèndòu [Erga bem alto a grande bandeira do socialismo com características chinesas: Esforce-se por uma nova vitória na construção de uma sociedade próspera de uma forma abrangente]. Zhōngguó rìbào 中国日报 [China Daily]. Recuperado de https://www.chinadaily. com.cn/hqzg/2007-10/25/content_6205616.htm [Acesso em 30 jul. 2020].

Jintao, H. (2012, nov., 17). 胡锦涛在中国共产党第十八次全国代表大会上的报告 Hújīntāo zài zhōngguó gòngchăndăng dì shíbā cì quánguó dàibiǎo dàhuì shàng de bàogào [Relatório de Hu Jintao no $18^{\circ}$ Congresso Nacional do Partido Comunista da China]. 新华社 Xìnhuá shè [Agência de Notícias Xinhua]. Recuperado de http://www.gov.cn/ldhd/2012-11/17/content_2268826.htm [Acesso em 30 jul. 2020].

Joint Chief of Staff. (2003, September 5). Joint publication 3-53: Doctrine for joint psychological operations. Recuperado de https://www.hsdl.org/?view\&did=472329

Joseph, W. A. (2019). Studying Chinese politics, In W. A. Joseph (Ed.), Politics in China: an introduction. $3^{\text {rd }}$ ed. London: Oxford University Press.

Jun, A. (2017, December 19). Why The Economist Failed to Grasp China's Influence? Global Times. Recuperado de http://www.globaltimes.cn/content/1081108. shtml. [Acesso em 10 fev. 2020].

Kennedy, S. (2010). The myth of the Beijing consensus. Journal of Contemporary China, $19,65,461-477$.

Keqiang, L. (2020，mai., 22). 政府工作报告-2020年5月 22 Zhèngfǔ gōngzuò bàogào-2020 nián 5 yuè 22 [Relatório de trabalho do governo: 22 de maio de 2020]. 新华网 Xinnhuá wăng [Xinhua]. Recuperado de http://www.xinhuanet.com/politics/2020lh/2020-05/22/c_1126018545.htm?baike [Acesso em 7 jul. 2020].

Kilbane, M. (2009). Military psychological operations as public diplomacy. In N. Snow \& P. M. Taylor (Eds.), Routledge handbook of public diplomacy (pp. 187-192). New York: Routledge.

Kobierecka, A. \& Kobierecki, M. M. (2021). Coronavirus diplomacy: Chinese medical assistance and its diplomatic implications. International Politics. doi: /10.1057/ s41311-020-00273-1.

Koetse, M. (2018). On 'Sharp Power' \& the China Threat 3.0: the West is mentally stuck in the Cold War Era. China Insight. Recuperado de https://www.whatsonweibo. 
com/on-sharp- power-the-china-threat-3-o-the-west-is-mentally-stuck-in-cold-war-era/ [Acesso em 10 fev. 2020].

Krippendorff, K. (2004). Content Analysis: an introduction to its methodology. 2nd ed. Thousand Oaks: Sage.

Landry, P. F. (2008). Decentralized authoritarism in China: the Communist Party's control of local elites in the post-Mao era. Cambridge: Cambridge University Press.

Lau, D. C. (2019). Introdução. In Confúcio, Os Anacletos (C. Chang, Trad.). Porto Alegre: LP\&M Editores. [Arquivo Kindle].

Leonard, Mark. 2002. Public diplomacy. London: Foreign Policy Centre.

Levitsky, S., \& Way, L. A. (2002, abr.). The rise of competitive authoritarism. Journal of Democracy, 13(2), 51-65.

Lewis, O. (2013). Net inclusion: new media's impact on deliberative politics in China. Journal of Contemporary Asia, 43(4), 678-708.

Li, Cheng. (2019). China's Communist Party-State: e Structure and Dynamics of Power. In Joseph, W. A. (Ed.), Politics in China: an introduction. $3^{\text {rd }}$ ed. New York: Oxford University Press.

Lipton, E. S. \& Barboza, D. (2007, jun. 19). As more toys are recalled, trail ends in China. New York Times. Recuperado de https://www.nytimes.com/2007/06/19/ business/worldbusiness/19toys.html [Acesso em 15 ago. 2020].

Lora, R. S. (2022). Atuação do Conselho Agropecuário do Sul (CAS) na inserção brasileira internacional. Revista de Política Agrícola, 31, 1, Forthcoming, 11 pp.

Luan, J. \& Sun, Y. (2012). 让世界了解中国共产党—“走进党的部门”系列活动案例分析 Ràng shìjiè liăojiě zhōngguó gòngchăndăng-“zǒu jìn dăng de bùmén” xìliè huódòng ànlì fēnxī [O Partido Comunista da China aberto ao mundo: estudo de caso das atividades do programa "Conhecendo os departamentos do partido". 公共外交季刊-杂志Gōnggòng wàijiāo jìkān-zázhì [Public Diplomacy Quartely], 11, 3, 34-40.

Ma, J., Lew, L. \& Jeong-Lee, L. (2020, mar., 22). A third of coronavirus cases may be 'silent carriers', classified Chinese data suggests. South China Morning Post. Recuperado de https://www.scmp.com/news/china/society/article/3076323/third-coronavirus-cases-may-be-silent-carriers-classified [Acesso em 20 jul. 2020].

Ma, Z. (2019). “锐实力”论与美国对华战略环境的转变. “Ruì shíli” lùn yǔ měiguó duì huá zhànlüè huánjìng de zhuănbiàn [A teoria do "sharp power" e a mudança do ambiente estratégico dos EUA em relação à China]. 特级教师马增书工作室科 学共Tèji jiàoshī măzēngshū gōngzuò shì kēxué gòngtóng. Recuperado de http:// dongxiaoqu.zhengzhong.cn/index.php? $\mathrm{m}=$ content\&c=index\&a=show\&cati$\mathrm{d}=116 \& \mathrm{id}=7992$ [Acesso em 20 ago. 2020].

Madrid-Morales, D. (2017). China's digital public diplomacy towards Africa: actors, messages and audiences. In K. Batchelor \& X. Zhang (Eds.), China-Africa Relations: Building Images through Cultural Co-operation, Media Representation and Communication. London: Routledge.

Magalhães, J. C. de (1982). A Diplomacia Pura. Lisboa: APRI.

Malone, G. D. (1985). Managing public diplomacy. The Washington Quartely, 8(3), 199123. 
Mandip, S. (2018). From Smart Power to Sharp Power: how China promotes her national interests. Journal of Defence Studies, 12(3) 5-25.

Martino, L. di (2020). The spectrum of listening. In N. Snow \& N. Cull (Eds.), Routledge handbook of public diplomacy. $2^{\text {nd }} \mathrm{ed}$. New York: Routledge.

Melchor, L. (2020). What is a science diplomat? The Hague Journal of Diplomacy, 15(3), 409-423. doi: 10.1163/1871191X-BJA10026.

Melissen, J. (2005). The new public diplomacy: between theory and practice. In J. Melissen (Ed.), The new public diplomacy: soft power in international relations. New York: Palgrave.

Melissen, J. \& Wang, J. (2019). Introduction: debating public diplomacy. The Hague Journal of Diplomacy, 14(1), 1-5.

Mendes, N. C. (2017). História e Conjuntura das Relações Internacionais. Lisboa: ISCSP.

Meng, K. (2019, out., 24).「一帶一路」登陸澳洲 中國「銳實力」挑戰西方 ‘Yīdài yīlù’dēnglù àozhōu zhōngguó `ruì shílìttiăozhàn xīfāng [A “One Belt One Road” chegou à Austrália: o "sharp power" da China desafia o Ocidente]. BBC China. Recuperado em https://www.bbc.com/zhongwen/trad/chinese-news-50171337 [Acesso em 20 ago. 2020].

Ministry of Foreign Affairs of the People's Republic of China. (2017). China's Policies on Asia-Pacific Security Cooperation. FMPRC. Recuperado de https://www.fmprc.gov.cn/mfa_eng/zxxx_662805/t1429771.shtml [Acesso em 15 ago. 2020].

Nye, J. S., Jr. (1991). Bound to Lead: the changing nature of American power. New York: Basic Books.

Nye, J. S., Jr. (2004). Soft Power: The Means to Success in World Politics. $4^{\text {th }}$ ed. New York: public Affairs.

Nye, J. S., Jr. (2008). Public Diplomacy and Soft Power. Annals, AAPSS, 616, 94-109.

Nye, J. S., Jr. (2011). The future of power. New York: Public Affairs.

Nye, J. S., Jr. (2018). China's Soft and Sharp Power. Project Syndicate. Recuperado de https://www.project-syndicate.org/commentary/china-soft-and-sharp-power-by-joseph-s--nye- 2018-01 [Acesso em 9 fev. 2020].

Nye, J. S., Jr. (2019). Soft power and public diplomacy revisited. The Hague Journal of Diplomacy, 17, 7-20.

Oxford Analytica. (2021). Vaccine diplomacy will earn China friends and money. Expert Briefings. doi: 10.1108/OXAN-DB261517.

Peng, W. (2019, mai., 2). Unpacking misconceptions. Beijing Review, 28. Recuperado de http://www.bjreview.com/CHINA_INSIGHT_2019/MAY_2019/201907/ t20190702_8001724 75.html. [Acesso em 9 fev. 2020].

People's Republic of China (PRC) (Zhōnghuá Rénmín Gònghéguó 中华人民共和国). (2004). Constitution of the People's Republic of China. Recuperado de http://www. npc.gov.cn/zgrdw/englishnpc/ Constitution/node_2825.htm [Acesso em 2 abr. 2020].

Postema, S. \& Melissen, J. (2021). UN celebrity diplomacy in China: activism, symbolism and national ambition online. International Affairs, 97, 3, 667-684. doi: 10.1093/ia/iiabo42 
Powers, S. \& Samuel-Azran, T. (2015). A microeconomic approach to international broadcasting. The Journal of International Communication, 21(1) 58-77.

Ramo J. C. (2004). The Beijing consensus. London: The Foreign Policy Centre.

Rawnsley, G. D. (2015). To know us is to love us: public diplomacy and international broadcasting in contemporary Russia and China. Politics, 35, 3-4, pp. 273-286.

Rawnsley, G. D. (2020). Communicating confidence: China's public diplomacy. In N. Snow \& N. Cull, Routledge handbook of public diplomacy. New York: Routledge.

Roy, D. (1996). The "China threat" issue. Asian Survey, 36(8), 758-771.

Santos, N. de A. e S. F. dos (2019). Soft and sharp power in area studies of China: the Chinese public diplomacy in the UNESCO creative cities network. Daxiyangguo Portuguese Journal of Asian Studies. doi:10.33167/1645-4677.DAXIYANGGUO2019.24/pp.73-101.

Santos, N. de A. e S. F. dos (2020a). COVID-19 \& Chinese public diplomacy: soft power, sharp power and ethics. Public Diplomacy Magazine, 23, 88-90.

Santos, N. de A. e S. F. dos (2020b). Crossroads between city diplomacy and city branding towards the future: case study on the film cities at UNESCO Creative Cities Network. Place Branding and Public Diplomacy. doi: 10.1057/s41254-020-00174-3.

Santos, N. de A. e S. F. dos (2020c). City diplomacy as tool for improving the EU-China cooperation: the Chinese and EU UNESCO creative cities. EU China Observer, 1.20, 9-12.

Santos, N. de A. e S. F. dos (2021a). Multi-level governance tackling the COVID-19 pandemic in China. Revista de Administração Pública, 55, 1, 95-110. doi: 10.1590/0034761220200494 .

Santos, N. de A. e S. F. dos (2021b). The interplay of soft power and sharp power in sport diplomacy: a conceptual framework. Journal of Global Sport Management (forthcoming). doi: 10.1080/24704067.2021.1952092.

Santos, N. de A. S. F. dos (2021c). Presidential public diplomacy 2.0: Seven lessons to prevent fire in Cyberspace. Journal of Public Diplomacy, 1(1), 36-56. doi: 10.23045/jpd.2021.1.1.036.

Scott-Smith, G. (2020). Exchange programs and public diplomacy. In N. Snow \& N. Cull (Eds.), Routledge handbook of public diplomacy. $2^{\text {nd }}$ ed. London: Routledge.

Selvage, D. (2021). Operation "Denver": The East German ministry for state security and the KGB's AIDS disinformation campaign, 1986-1989 (Part 2). Journal of Cold War Studies, 23(3), 4-80. doi: 10.1162/jcws_a_01024

Sharp, P. (2005). Revolutionary states, outlaw regimes and the techniques of public diplomacy. In J. Melissen (Ed.), The new public diplomacy: soft power in international relations. New York: Palgrave.

Si, L. (2018, fev., 13). Spotlight: who's behind the term "sharp power"? Xinhua. Retrieved from http://www.xinhuanet.com/english/2018-02/13/c_136972986.htm. [Acesso em 9 fev. 2020].

Smith, G. (2018, mai, 28). The Wechuan earthquake, ten years on. The Lowy Institute. Recuperado em https://www.lowyinstitute.org/the-interpreter/wenchuan-earthquake-ten-years [Acesso em 15 ago. 2020]. 
Snow, N. (2020). Rethinking public diplomacy in the 2020s. In N. Snow \& N. Cull (Eds.), Routledge Handbook of public diplomacy. $2^{\text {nd }}$ ed. New York: Routledge.

Snow, S. (2009). Rethinking public diplomacy. In N. Snow \& Taylor, P. M. (Eds.), Routledge handbook of public diplomacy. New York: Routledge.

State Council Information Office of China (SCIO) (Guówùyuàn Xīnwén Bàngōngshì 國 務院新聞辦公室). (2020, jun., 7). White Paper - Full Text on Fighting COVID-19: China in Action. SCIO. Recuperado de http://english.scio.gov.cn/whitepapers/2020-06/07/content_76135269.htm [Acesso em 30 jul. 2020].

Sun, H. (2020). 新冠肺炎与人类命运共同体建设 Xīnguān fèiyán yǔ rénlèi mìngyùn gòngtóngtǐ jiànshè [A moléstia causada pelo novo coronavírus e a construção de uma comunidade com um futuro compartilhado para a humanidade]. 公共 外交季刊-杂志 Gōnggòng wàijiāo jìkān-zázhì [Public Diplomacy Quartely], 2020, 1, 18-22, 125 .

Taehwan, K. (2018, jun., 18). Authoritarian Sharp Power: Comparing China and Russia. The Asan Open Forum. Retrieved from http://www.theasanforum.org/authoritarian-sharp-power- comparing-china-and-russia/ [Acesso em 9 fev. 2020].

Tang, L. \& Li, H. (2011). Chinese corporate diplomacy: Huawei's CSR discourse in Africa. In J. Wang, Soft power in China: public diplomacy through communication. New York: Palgrave.

The Economist [Editorial]. (2017, dez., 14). What to do about China's "sharp power". The Economist. Retrieved from https://www.economist.com/leaders/2017/12/14/ what-to-do-about- chinas-sharp-power [Acesso em 9 fev. 2020].

The Economist. (2021). Democracy Index 2020: In sickness and in health? London: The Economist Intelligence Unit.

The Lancet (2020). COVID-19 and China: lessons and the way forward. The Lancet, 396(10246), 213.

Tsang, T. K., Wu, P., Lin, Y., Lau, E. H. Y., Leung, G. M., Cowling, B. J. (2020). Effect of changing case defininitioons for COVID-19 on the epidemic curve and transmission parameters in mainland China: a modelling study. The Lancet Public Health, 5 (5), e289-296.

Tufekci, Z. (2020, fev., 22). How the coronavirus revealed authoritarianism's fatal flaw. The Atlantic. Recuperado de https://www.theatlantic.com/technology/archive/2020/02/coronavirus-and-blindness-authoritarianism/606922/ [Acesso em 10 jul. 2020].

US Department of the Army (2003, December 31). FM 3-05.301 (FM 33-1-1) MCRP 3-40.6A: Psychological operations tactics, techniques, and procedures. Recuperado de https://fas.org/irp/doddir/army/fm3-05-301.pdf

US News. (2021). 2020 Best Countries: subranking power. US News. Recuperado de https://www.usnews.com/news/best-countries/power-rankings [Acesso em 7 jul. 2021].

Velikaya, A., and Simons, G. 2020. Russia's public diplomacy: Evolution and practice. Cham: Palgrave.

Verma, R. (2020). China's 'mask diplomacy' to change the COVID-19 narrative in Europe. Asia Europe Journal, 18, 205-209. doi: 10.1007/s10308-020-00576-1.

Walker, C. (2018). What is "sharp power"? Journal of Democracy, 29(3), 9-23. 
Walker, C. \& Ludwig, J. (2017a, nov., 16). The meaning of sharp power: how authoritarian states project influence. Foreign Affairs. Recuperado de https://www. foreignaffairs.com/articles/china/2017-11-16/meaning-sharp-power [Acesso em 9 fev. 2020].

Walker, C. \& Ludwig, J. (2017b). From 'Soft Power' to 'Sharp Power': rising authoritarian influence in the democratic world. In Sharp Power: rising authoritarian influence. Washington: NED. Recuperado de https:// www.ned.org/wp-content/ uploads/2017/12/Sharp-Power-Rising- Authoritarian-Influence-Full-Report.pdf [Acesso em 9 fev. 2020].

Walker, C., Kalathil, S., Ludwig, J. (2020). The cutting edge of sharp power. Journal of Democracy, 31(1), 124-137.

Wang, J. (2011). Introduction: China's search of soft power. In J. Wang, Soft power in China: public diplomacy through communication. New York: Palgrave.

Wang, J. (2013). Shapping China's global imagination: branding nation at the World Expo. New York: Palgrave.

Wang, J., Zhu, E., \& Umlaut, T. (2020). How China built two coronavirus hospitals in just over a week. Wall Street Journal. Recuperado de https://www.wsj.com/ articles/how-china-can-build-a-coronavirus-hospital-in-10-days-11580397751 [Acesso em 7 jul. 2021].

Wang, K. (2020). 习近平对新型冠状病毒感染的肺炎疫情作出重要指示 强调要把人民群 众生命安全和身体健康放在第一位 坚决遏制疫情蔓延势头 Xíjìnpíng duì xīnxíng guānzhuàng bìngdú gănrăn de fèiyán yìqíng zuòchū chóng yào zhǐshì qiángdiào yào bă rénmín qúnzhòng shēngmìng ānquán hé shēntǐ jiànkāng fàng zài dì yī wèi jiānjué èzhì [Instruções de Xi Jinping sobre a epidemia causada pelo novo coronavírus: a segurança e a saúde das pessoas devem ser colocadas em primeiro lugar, reduzindo resolutamente a propagação da epidemia]. 中国共产 党 Zhōngguó Gòngchăndăng [Partido Comunista da China]. Recuperado de http:// jhsjk.people.cn/article/31557455 [Acesso em 23 ago. 2020].

Wang, N. (2018). "First lady diplomacy" and the construction of national image. Place Branding and Public Diplomacy, 14, 125-136.

Wang, Y. (2008). Public diplomacy and the rise of Chinese soft power. Annals AAPSS 616: 257-273.

Weiwei, Z. (2009). Improving public diplomacy with Chinese characteristics. China Internacional Studies, 157.

Wilder-Smith, A. \& Freedman, D. O. (2020). Isolation, quarantine, social distancing and community containment: pivotal role for old-style public health measures in the novel coronavirus (2019-nCoV) outbreak. Journal of Travel Medicine, 2020, 1-4, doi: 10.1093/jtm/taaa020.

Winter, T. (2016, mar., 19). One Belt, One Road, one heritage: cultural diplomacy and the silk road. The Diplomat. Recuperado de https://thediplomat.com/2016/03/ one-belt-one-road-one-heritage-cultural-diplomacy-and-the-silk-road/ [Acesso em 15 ago. 2020].

Wong, J. \& Yongnian, Z. (2004)SARS and governance in China. In J. Wong \& Z. Yongnian (Eds.), The SARS epidemic: challenges to China's crisis management. Singapore: World Scientific Publishing. 
World Bank. (2021a). Population, total: China. The World Bank Data. Recuperado de https://data.worldbank.org/indicator/SP.POP.TOTL?locations=CN\&most_recent _value_desc=true [Acesso em 7 jul. 2021].

World Bank. (2021b). GDP (current, US\$): China. The World Bank Data. Recuperado de https://data.worldbank.org/indicator/NY.GDP.MKTP.CD?locations=CN [Acesso em 7 jul. 2021].

World Health Organization (WHO). (2020a). Report of the WHO-China joint mission on coronavirus disease 2019 (COVID-19). WHO. Recuperado de https://www. who.int/docs/default-source/coronaviruse/who-china-joint-mission-on-covid-19-final-report.pdf [Acesso em 10 mar. 2020].

World Health Organization (WHO). (2020b). Archived: WHO timeline - COVID-19. WHO. Recuperado de https://www.who.int/news-room/detail/27-04-2020-who-timeline---covid-19 [Acesso em 20 jul. 2020].

World Health Organization (WHO). (2021a, jul., 6). COVID-19 weekly epidemiological update. WHO. Recuperado de https://www.who.int/publications/m/item/ weekly-epidemiological-update-on-covid-19---6-july-2021 [Acesso em 7 jul. 2021].

World Health Organization (WHO). (2021b, jul., 6). WHO Coronavirus (COVID-19) Dashboard. WHO. Recuperado de https://covid19.who.int/table [Acesso em 7 jul. 2021].

Wu, C., Shi, Z., Wilkes, R., Wu, J., Gong, Z., He, N., Xiao, Z., Zhang, X., Lai, W., Zhou, D., Zhao, F., Yin, X., Xiong, P., Zhou, H., Chu, Q., Cao, L., Tian, R., Tan, Y., Yang, L., He, Z., Fairbrother, M., Mews, J., \& Giordano, G. N. (2021) Chinese Citizen Satisfaction with Government Performance during COVID-19. Journal of Contemporary China. doi: 10.1080/10670564.2021.1893558

Xinhua. (2020, jan., 26). 李克强主持召开中央应对新型冠状病毒感染肺炎疫情工作领 导小组会议 Lǐkèqiáng zhǔchí zhàokāi zhōngyāng yìngduì xīnxíng guānzhuàng bìngdú gănrăn fèiyán yìqíng gōngzuò lǐngdăo xiăozǔ huìyì [Li Keqiang chaired the central leading group for COVID-19 prevention and control].新华网 Xīnhuá wăng [Xinhua]. Recuperado de http://www.xinhuanet.com/politics/ 2020-01/26/c_1125504004.htm [Acesso em 2 mai. 2020].

$\mathrm{Xu}$, J. \& Cao, Y. (2019). The image of Beijing in Europe: findings from The Times, Le Figaro, Der Spiegel from 2000 to 2015. Place Branding and Public Diplomacy, 15, 185-197.

Yamei (2018, mar., 2). "Sharp power" a new version of "China threat" rhetoric: spokesperson. Xinhua. Recuperado de http://www.xinhuanet.com/english/ 2018-03/02/c_137011743.htm. [Acesso em 9 fev. 2020].

Yilong, Z. (2012). 加强研究,拓展侨务公共外交 Jiāqiáng yánjiū, tàzhăn qiáowù gōnggòng wàijiāo [Fortalecimento e expansão da diplomacia pública chinesa no exterior]. 公共外交季刊-杂志 Gōnggòng wàijiāo jìkān-zázhì [Public Diplomacy Quartely], 9, 1, 50-52.

Yin, R. (2018). Case study research and applications: design and methods. $6^{\text {th }}$ ed. London: Sage. [Arquivo Kindle].

Yongnian, Z. \& Fook, L. L. (2004). SARS and China's political system. In J. Wong \& Z. Yongnian (Eds.), The SARS epidemic: challenges to China's crisis management. Singapore: World Scientific Publishing. 
Zastrow, M. (2020). How South Korea prevented a coronavirus disaster - and why the battle isn't over. National Geographic. Recuperado de https://www.nationalgeographic.com/science/2020/05/how-south-korea-prevented-coronavirus-disaster-why-battle-is-not-over/ [Acesso em 9 jul. 2020].

Zelcer, M., VanPelt, G., \& Casey, D. (2018). Military psychological operations: Ethics and policy considerations. In D. Boonin (Ed.), The Palgrave handbook of philosophy and public policy (pp. 111-122). Cham: Palgrave.

Zhao, K. (2016). China's rise and its discursive power strategy. China Political Science Review. doi: 10.1007/s41111-016-0027-x.

Zhao, K. and Chen, W. [Zhàokějīn, Chénwéi 赵可金陈维]. “City Diplomacy: Exploring the Role of Global Cities" [Chéngshì wàijiāo: Tànxún quánqiú dūshì de wàijiāo juésè 城市外交:探寻全球都市的外交角色]. Diplomatic Review [Wàijiāo pinglùn 外交评论] 6 (2013), 67.

Zhao, S. (2020). Rhetoric and reality of China's global leadership in the context of COVID-19: Implications for the US-led World Order and Liberal Globalization. Journal of Contemporary China. doi: 10.1080/10670564.2020.1790900.

Zhao, T. (2018). Tianxia, tout sous un même ciel. Paris: Éditions du CERF.

Zheng, Y. \& Tok, S. K. (2007). 'Harmonious society' and 'harmonious world': China's policy discourse under Hu Jintao (Briefing Series issue 26). University of Nottingham, Nottingham, UK.

\section{Sobre os autores}

NIEDJA DE ANDRADE E SILVA FORTE DOS SANTOS é Investigadora colaboradora do Centro de Administração e Políticas Públicas (CAPP-ISCSP/FCT), Universidade de Lisboa. Membro da International Studies Association (ISA), Associação Portuguesa de Ciência Política (APCP) e International Political Science Association (IPSA). É Doutoranda em relações internacionais na mesma universidade. Licenciada e mestre em direito no Brasil com equivalência de ambos os graus pela Faculdade de Direito da Universidade de Coimbra. Possui especialização em Direito Empresarial pela Universidade de Coimbra e Master Business Administration pela Fundação Getúlio Vargas. Revisora do Journal of Public Diplomacy. Practitioner em diplomacia pública na UNESCO Creative Cities Network e em diplomacia corporativa no setor privado brasileiro. Atuou como Secretária Adjunta de Desenvolvimento Económico e Inovação e como Diretora de Inovação Económica na Prefeitura Municipal de Santos, Brasil. As suas áreas de interesse incluem a Diplomacia Pública, Gestão de Riscos, Anticorrupção e China.

[ORCID ID: https://orcid.org/oooo-00o2-7313-2296]

SANDRA MARIA RODRIGUES BALÃO é Investigadora do Centro de Administração e Políticas Públicas (CAPP-ISCSP/FCT) e do Instituto do Oriente (IO-ISCSP/FCT) da Universidade de Lisboa, assim como do Centro de Investigação e Desenvolvimento do Instituto Universitário Militar (CIDIUM-IUM). Investigadora e membro do Conselho Coordenador e do Conselho Científico do Colégio de Estudos Polares e Ambientes 
Extremos da Universidade de Lisboa (Polar2E-ULisboa) é, também, representante nacional no Social and Human Working Group do International Arctic Science Committee (IASC-SHWG). É, ainda, membro e investigadora do Northern Research Forum da Universidade do Árctico (TNGS-NRF/UArctic). É Doutorada em Ciências Sociais, Mestre em Ciência Política e Licenciada em Gestão e Administração Pública, com uma especialização em Gestão de Recursos Humanos. As suas áreas de interesse situam-se no âmbito dos Estudos Políticos, Estratégicos, Internacionais e de Área numa perspetiva multinível e multidimensão, com particular destaque para o Árctico, Geopolítica, Geoestratégia, Governance e Diplomacia dos “novos” espaços/ domínios/âmbitos de Segurança e Defesa.

[ORCID ID: https://orcid.org/oooo-0002-2999-1157]

\section{About the authors}

NIEDJA DE ANDRADE E SILVA FORTE DOS SANTOS is a Researcher at the Center for Administration and Public Policies (CAPP-ISCSP/FCT), University of Lisbon. Member of the International Studies Association (ISA), Portuguese Political Science Association (APCP) and International Political Science Association (IPSA). PhD Candidate in International Relations at the same university. She is undergraduated in Law and holds a Master in Law (MSc) degree, both recognized by the University of Coimbra Law School. She got a Specilization in Corporate Law at the University of Coimbra Law School and a Master Business Administration (MBA) Specialization at the Getulio Vargas Foundation (FGV). Reviewer at the Journal of Public Diplomacy. Practitioner in public diplomacy at the UNESCO Creative Cities Network and in corporate diplomacy in the Brazilian private sector. Former Deputy Secretary of Economic Development and Innovation and Director of Innovation at Santos City Hall (Brazil). Her main interests include Public Diplomacy, Risk Management, Anti-corruption and China.

[ORCID ID: https://orcid.org/oooo-0002-7313-2296]

SANDRA MARIA RODRIGUES BALÃO is a Researcher at the Center for Administration and Public Policies (CAPP-ISCSP/FCT) and Orient Institute (IO-ISCSP/FCT), both at Institute of Social and Political Sciences, University of Lisbon as well as at the Center for Research and Development of the Military Universitary Institute (CIDIUM-IUM). Researcher and member of the Coordinator Board and of the Scientific Board at the College of Polar Studies and Extreme Environments (Polar2E-University of Lisbon) is, also, the National Representative at the Social and Human Working Group at the International Arctic Science Committee (SHWG-IASC). Moreover, she is a member of the Northern Research Forum at the Arctic University (TNGS-NRF/UArctic). PhD in Social Sciences with a MSc in Political Science. She is undergraduated in Public Administration and Management and got a Specialization in Human Resources Management. Her main interests are Political and Strategic Studies considered both in a multilevel and multidimensional perspective, namely the Arctic region, Geopolitics, Geostrategy, Governance and Diplomacy of 'new' strategically relevant spaces/domains in the Political, Strategic, International and Area Studies.

[ORCID ID: https://orcid.org/oooo-0002-2999-1157] 


\section{APÊNDICE}

\section{Informações selecionadas da working sheet para composição do estudo de caso}

Quadro A (QA) - Frente "Saúde e pesquisa"

\begin{tabular}{|c|c|c|c|c|c|}
\hline \multicolumn{2}{|c|}{ Informação } & \multirow{2}{*}{$\begin{array}{l}\text { Ferramenta } \\
\text { diplomacia } \\
\text { científica }\end{array}$} & \multirow{2}{*}{$\begin{array}{l}\text { Apelo }^{\mathrm{a}} \\
\text { Soft power } \\
\text { (A) }\end{array}$} & \multirow{2}{*}{$\begin{array}{l}\text { Fonte Primáriab } \\
\text { SCIO, 2020, pp. 7, } 12\end{array}$} & \multirow{2}{*}{$\begin{array}{l}\begin{array}{l}\text { Fonte } \\
\text { secundária }\end{array} \\
\text { WHO, 2020a, p. } 14\end{array}$} \\
\hline 1 & $\begin{array}{l}\text { Compartilhamento do } \\
\text { sequenciamento genômico } \\
\text { do novo coronavírus }\end{array}$ & & & & \\
\hline 2 & $\begin{array}{l}\text { Compartilhamento dos } \\
\text { protocolos de diagnóstico }\end{array}$ & $\begin{array}{l}\text { diplomacia } \\
\text { científica }\end{array}$ & $\begin{array}{l}\text { Soft power } \\
\text { (A) }\end{array}$ & $\begin{array}{l}\text { Keqiang, 2020, pt. } \\
\text { 8; SCIO, 2020, p. } 43\end{array}$ & $\begin{array}{l}\text { WHO, } 2020 a, \text { pp. } \\
\text { 14, 15; CWI et al., } \\
2020 \text {, pp. 3-4 }\end{array}$ \\
\hline 3 & $\begin{array}{l}\text { Divulgações sobre } \\
\text { investigação } \\
\text { epidemiológica, aprimorada } \\
\text { tecnologicamente (big data) }\end{array}$ & $\begin{array}{l}\text { diplomacia } \\
\text { científica }\end{array}$ & $\begin{array}{l}\text { Soft power } \\
\text { (A) }\end{array}$ & SCIO, 2020, p. 8 & $\begin{array}{l}\text { WHO, 2020a, p. 15; } \\
\text { CWI et al., 2020, } \\
\text { p. } 11\end{array}$ \\
\hline 4 & $\begin{array}{l}\text { Desenvolvimento e constante } \\
\text { aperfeiçoamento dos kits de } \\
\text { testagem }\end{array}$ & $\begin{array}{l}\text { diplomacia } \\
\text { científica }\end{array}$ & $\begin{array}{l}\text { Soft power } \\
\text { (A) }\end{array}$ & $\begin{array}{l}\text { Keqiang, 2020, pt. } \\
\text { 8; SCIO, 2020, p. } 13\end{array}$ & $\begin{array}{l}\text { WHO, 2020a, p. 15; } \\
\text { CWI et al., 2020, } \\
\text { p. } 9\end{array}$ \\
\hline 5 & $\begin{array}{l}\text { Compartilhamento dos } \\
\text { protocolos de medidas de } \\
\text { controle de transmissão }\end{array}$ & $\begin{array}{l}\text { diplomacia } \\
\text { científica }\end{array}$ & $\begin{array}{l}\text { Soft power } \\
\text { (A) }\end{array}$ & $\begin{array}{l}\text { Keqiang, 2020, pt. } \\
\text { 8; SCIO, 2020, p. } 10\end{array}$ & WHO, 2020a, p. 15 \\
\hline 6 & $\begin{array}{l}\text { Realização de pesquisas } \\
\text { científicas, incluindo vacinas, } \\
\text { inclusive com parcerias } \\
\text { internacionais }\end{array}$ & $\begin{array}{l}\text { diplomacia } \\
\text { científica }\end{array}$ & $\begin{array}{l}\text { Soft power } \\
\text { (A) }\end{array}$ & Keqiang, 2020, pt. 1 & $\begin{array}{l}\text { WHO, 2020a, p. 15; } \\
\text { CWI et al., 2020, } \\
\text { pp. 14-18 }\end{array}$ \\
\hline 7 & $\begin{array}{l}\text { Desenvolvimento de } \\
\text { protocolos de tratamento }\end{array}$ & $\begin{array}{l}\text { diplomacia } \\
\text { científica }\end{array}$ & $\begin{array}{l}\text { Soft power } \\
\text { (A) }\end{array}$ & $\begin{array}{l}\text { Keqiang, 2020, pt. } \\
\text { 8; SCIO, 2020, p. } 8\end{array}$ & $\begin{array}{l}\text { WHO, 2020a, p. 15; } \\
\text { CWI et al., 2020, } \\
\text { p. } 12\end{array}$ \\
\hline 8 & $\begin{array}{l}\text { Realização de conferências } \\
\text { online por especialistas da } \\
\text { china com experts de todo o } \\
\text { mundo }\end{array}$ & $\begin{array}{l}\text { diplomacia } \\
\text { científica }\end{array}$ & $\begin{array}{l}\text { Soft power } \\
\text { (A) }\end{array}$ & $\begin{array}{l}\text { Keqiang, 2020, pt. } \\
\text { 8; SCIO, 2020, pp. } \\
\text { 8-10 }\end{array}$ & $\begin{array}{l}\text { CWI et al., 2020, } \\
\text { p. } 3\end{array}$ \\
\hline 9 & $\begin{array}{l}\text { Protocolos de equipamentos } \\
\text { de proteção para } \\
\text { trabalhadores da linha de } \\
\text { frente médica }\end{array}$ & $\begin{array}{l}\text { diplomacia } \\
\text { científica }\end{array}$ & $\begin{array}{l}\text { Soft power } \\
\text { (A) }\end{array}$ & SCIO, 2020, p. 59 & $\begin{array}{l}\text { CWI et al., 2020, } \\
\text { pp. 21-22 }\end{array}$ \\
\hline 10 & $\begin{array}{l}\text { Promoção de estudos } \\
\text { emergenciais sobre } \\
\text { terapêutica da doença }\end{array}$ & $\begin{array}{l}\text { diplomacia } \\
\text { científica }\end{array}$ & $\begin{array}{l}\text { Soft power } \\
\text { (A) }\end{array}$ & SCIO, 2020, p. 16 & WHO, 2020a, p. 16 \\
\hline
\end{tabular}

Fonte: elaborado pelas autoras a partir das fontes primárias e secundárias relacionadas no quadro 


\section{Quadro B (QB) - Frente "Monitoramento social"}

\begin{tabular}{|c|c|c|c|c|c|}
\hline \multicolumn{2}{|c|}{ Informação } & \multirow{2}{*}{$\begin{array}{l}\text { Ferramenta } \\
\text { pressão }\end{array}$} & \multirow{2}{*}{$\begin{array}{l}\text { Apelo }^{\mathbf{a}} \\
\text { Sharp power } \\
\text { (I) }\end{array}$} & \multirow{2}{*}{$\begin{array}{l}\text { Fonte Primáriab }^{\text {SCIO, 2020, pp. 9-10 }} \\
\text { SC }\end{array}$} & \multirow{2}{*}{$\begin{array}{l}\text { Fonte secundária } \\
\text { WHO, 2020a, p. 15; } \\
\text { CWI et al., 2020, p. } 6\end{array}$} \\
\hline 1 & $\begin{array}{l}\text { Implantação de check points para } \\
\text { testagem/medição de temperatura } \\
\text { obrigatória em fronteiras e nas cidades }\end{array}$ & & & & \\
\hline 2 & $\begin{array}{l}\text { Implantação de quarentena } \\
\text { obrigatória }\end{array}$ & $\begin{array}{l}\text { constrição de } \\
\text { movimentação }\end{array}$ & $\begin{array}{l}\text { Sharp power } \\
\text { (D) }\end{array}$ & SCIO, 2020, p. 12, 19 & WHO, 2020a, p. 15 \\
\hline 3 & $\begin{array}{l}\text { Restrição de locomoção em Wuhan, } \\
\text { com exigência de autorização do } \\
\text { governo (QR Code) }\end{array}$ & $\begin{array}{l}\text { constrição de } \\
\text { movimentação }\end{array}$ & $\begin{array}{l}\text { Sharp power } \\
\text { (D) }\end{array}$ & SCIO, 2020, pp. 11-12 & $\begin{array}{l}\text { WHO, 2020a, p. 15; } \\
\text { CWI et al., 2020, pp. 6-11 }\end{array}$ \\
\hline 4 & $\begin{array}{l}\text { Rastreamento tecnológico (AI e big } \\
\text { data) de pessoas contaminadas e } \\
\text { contatos próximos }\end{array}$ & espionagem & $\begin{array}{l}\text { Sharp power } \\
\text { (D) }\end{array}$ & SCIO, 2020, p. 11 & WHO, 2020a, p. 15 \\
\hline 5 & $\begin{array}{l}\text { Isolamento compulsório de pessoas } \\
\text { contaminadas e seus próximos, } \\
\text { inclusive em áreas pré-determinadas }\end{array}$ & $\begin{array}{l}\text { constrição de } \\
\text { movimentação }\end{array}$ & $\begin{array}{l}\text { Sharp power } \\
\text { (D) }\end{array}$ & $\begin{array}{l}\text { Keqiang, } 2020, \text { pt. } 1 \text {; } \\
\text { SCIO, 2020, p. } 11\end{array}$ & $\begin{array}{l}\text { WHO, 2020a, p. 15; } \\
\text { CWI et al., 2020, pp. } 7,11\end{array}$ \\
\hline 6 & $\begin{array}{l}\text { Proibição de reuniões coletivas e } \\
\text { cancelamento de grandes eventos }\end{array}$ & $\begin{array}{l}\text { constrição de } \\
\text { movimentação }\end{array}$ & $\begin{array}{l}\text { Sharp power } \\
\text { (D) }\end{array}$ & SCIO, 2020, p. 33 & $\begin{array}{l}\text { WHO, 2020a, p. 15; } \\
\text { CWI et al., 2020, p. } 7\end{array}$ \\
\hline 7 & $\begin{array}{l}\text { Confinamento obrigatório (lockdown) } \\
\text { em Wuhan, com grande adesão da } \\
\text { população }\end{array}$ & $\begin{array}{l}\text { constrição de } \\
\text { movimentação }\end{array}$ & $\begin{array}{l}\text { Sharp power } \\
\text { (D) }\end{array}$ & Keqiang, 2020, pt. 1 & $\begin{array}{l}\text { WHO, 2020a, p. 15; } \\
\text { CWI et al., 2020, p. } 5\end{array}$ \\
\hline 8 & $\begin{array}{l}\text { Fechamento de atividades de lazer e } \\
\text { consumo (cinema, teatros, academias, } \\
\text { shoppings, etc.) }\end{array}$ & censura & $\begin{array}{l}\text { Sharp power } \\
\text { (I) }\end{array}$ & SCIO, 2020, p. 33 & $\begin{array}{l}\text { WHO, 2020a, p. 15; } \\
\text { CWI et al., 2020, p. } 7\end{array}$ \\
\hline 9 & $\begin{array}{l}\text { Rastreamento tecnológico (AI e big } \\
\text { data) da população de risco para a } \\
\text { doença }\end{array}$ & espionagem & $\begin{array}{l}\text { Sharp power } \\
\text { (D) }\end{array}$ & SCIO, 2020, p. 14 & WHO, 2020a, p. 15 \\
\hline 10 & Uso obrigatório de máscaras & pressão & $\begin{array}{l}\text { Sharp power } \\
\text { (I) }\end{array}$ & $\begin{array}{l}\text { SCIO, 2020, pp. } \\
33,55\end{array}$ & CWI et al., 2020, p. 3 \\
\hline 11 & Homeoffice obrigatório & censura & $\begin{array}{l}\text { Sharp power } \\
\text { (I) }\end{array}$ & Keqiang, 2020, pt. 1 & CWI et al., 2020, p. 7 \\
\hline 12 & Fechamento de escolas & censura & $\begin{array}{l}\text { Sharp power } \\
\text { (I) }\end{array}$ & Keqiang, 2020, pt. 1 & CWI et al., 2020, p. 7 \\
\hline 13 & $\begin{array}{l}\text { Política de ampla testagem obrigatória, } \\
\text { inclusive estrangeiros desembarcados } \\
\text { na China }\end{array}$ & pressão & $\begin{array}{l}\text { Sharp power } \\
\text { (I) }\end{array}$ & SCIO, 2020, p. 24 & CWI et al., 2020, p. 8 \\
\hline
\end{tabular}

Fonte: elaborado pelas autoras a partir das fontes primárias e secundárias relacionadas no quadro 


\section{Quadro C (QC) - Frente "Governança pública"}

\section{Informação}

$1 \quad$ Política nacional (Xi Jinping): vidas das pessoas em primeiro lugar, como missão do "futuro compartilhado para a humanidade"

2 Estabelecimento do programa "wartime pandemic command system"

3 Criação do grupo de liderança da resposta à COVID-19, sob coordenação do premier (mecanismo estratégico)

4 Adiamento do feriado de primavera

política

política

política
Fonte

Primáriab

narrativa e Soft power Keqiang, 2020, pt. 1,

(A)

narrativa

(A)

Soft power

(A)

Apelo

Soft power

Keqiang, 2020, pt. 1;

CWI et al., 2020, p. 24

pt. 8; SCIO, 2020, pp.

4, 11, 19, 20

Keqiang, 2020, pt. 1

CWI et al., 2020, p. 23

Fonte

secundária

CWI et al., 2020, p. 23

SCIO, 2020, p. 9

Soft power

Keqiang, 2020, pt. 1;

WHO, 2020a, p. 15

(A)

SCIO, 2020, p. 33

5 Campanhas educativas de prevenção

política

Soft power SCIO, 2020, p. 11

(A)

pressão

Sharp power Keqiang, 2020, pt. 1,

(I)

pt. 8; SCIO, 2020,

, 2020a, p. 15; médicos nos hospitais de Hubei, através de esforço nacional

pp. 11,48

7 Construção de novos hospitais em 10 dias pressão

Sharp power Keqiang, 2020, pt. 1; WHO, 2020a, p. 15;

(I) SCIO, 2020, p. 11

CWI et al., 2020, p. 20

8 Gestão para manutenção do fornecimento pressão

Sharp power Keqiang, 2020, pt. 1

WHO, 2020a, p. 15;

de commodities para a sociedade

(I)

CWI et al., 2020,

(sustentabilidade social e económica)

pp. $22-23$

9 Gestão para evitar altas de preços em

pressão

Sharp power Keqiang, 2020, pt. 1;

WHO, 2020a, p. 15; decorrências das restrições impostas pela

(I) SCIO, 2020, p. 36

CWI et al., 2020, p. 19 crise, inclusive com punições severas em casos abusivos

10 Governança para promover o apoio das demais províncias à Hubei, através do

pressão

Sharp power Keqiang, 2020, pt. 1

WHO, 2020a, p. 15

fornecimento de suprimentos médicose

(I) commodities em geral

11 Coletivas de imprensa diárias com o SCIO e a Província de Hubei para atualização, envolvendo jornalistas estrangeiros media estrangeiros

na China
Soft power SCIO, 2020, pp. 16, 41 CWI et al., 2020, p. 2

diplomacia Soft power SCIO, 2020, p. 8

(A)
CWI et al., 2020, p. 2 Saúde com atualização diária sobre a doença científica 


\begin{tabular}{|c|c|c|c|c|c|}
\hline \multicolumn{2}{|c|}{ Informação } & \multirow{2}{*}{$\begin{array}{l}\text { Ferramenta } \\
\text { narrativa }\end{array}$} & \multirow{2}{*}{$\begin{array}{l}\text { Apelo } \\
\text { Soft power } \\
\text { (A) }\end{array}$} & \multirow{2}{*}{$\begin{array}{l}\text { Fonte } \\
\text { Primáriab } \\
\text { Keqiang, 2020, pt. } 4\end{array}$} & \multirow{2}{*}{$\begin{array}{l}\text { Fonte } \\
\text { secundária } \\
\text { CWI et al., 2020, p. } 3\end{array}$} \\
\hline 13 & $\begin{array}{l}\text { Revisão de dados estatísticos de número de } \\
\text { casos com apoio tecnológico }\end{array}$ & & & & \\
\hline 14 & $\begin{array}{l}\text { Gestão da distribuição de informações para } \\
\text { a grande imprensa, inclusive internacional, } \\
\text { e para as redes sociais, com alvo na opinião } \\
\text { pública }\end{array}$ & $\begin{array}{l}\text { media } \\
\text { estrangeiros } \\
\text { na China }\end{array}$ & $\begin{array}{l}\text { Soft power } \\
\text { (I) }\end{array}$ & Keqiang, 2020, pt. 1 & CWI et al., 2020, p. 4 \\
\hline 15 & $\begin{array}{l}\text { Recrutamento de profissionais de saúde em } \\
\text { toda China para atuação em Hubei, incluindo } \\
\text { o Exército de Libertação Popular da China }\end{array}$ & pressão & $\begin{array}{l}\text { Sharp power } \\
\text { (I) }\end{array}$ & $\begin{array}{l}\text { Keqiang, } 2020 \text {, pt. } 1 \text {; } \\
\text { SCIO, 2020, p. } 12\end{array}$ & CWI et al., 2020, p. 19 \\
\hline 16 & $\begin{array}{l}\text { Gestão para garantia de fabricação de } \\
\text { suprimentos médicos, inclusive por } \\
\text { indústrias de outros ramos }\end{array}$ & pressão & $\begin{array}{l}\text { Sharp power } \\
\text { (I) }\end{array}$ & $\begin{array}{l}\text { Keqiang, 2020, pt. 8; } \\
\text { SCIO, 2020, p. } 49\end{array}$ & CWI et al., 2020, p. 20 \\
\hline 17 & $\begin{array}{l}\text { Incentivos ao desenvolvimento de } \\
\text { tecnologias contactless para e-commerce e } \\
\text { logística }\end{array}$ & $\begin{array}{l}\text { diplomacia } \\
\text { económica }\end{array}$ & $\begin{array}{l}\text { Soft power } \\
\text { (A) }\end{array}$ & Keqiang, 2020, pt. 4 & CWI et al., 2020, p. 23 \\
\hline 18 & $\begin{array}{l}\text { Medidas para preservação da economia e } \\
\text { manutenção de empregos }\end{array}$ & política & $\begin{array}{l}\text { Soft power } \\
\text { (A) }\end{array}$ & $\begin{array}{l}\text { Keqiang, 2020, pt. 2, } \\
\text { pt. 8; SCIO, 2020, } \\
\text { pp. } 19,21\end{array}$ & CWI et al., 2020, p. 26 \\
\hline 19 & $\begin{array}{l}\text { Relacionamento permanente com a WHO, } \\
\text { com objetivo de cooperação internacional }\end{array}$ & $\begin{array}{l}\text { diplomacia } \\
\text { científica }\end{array}$ & $\begin{array}{l}\text { Soft power } \\
\text { (A) }\end{array}$ & SCIO, 2020, pp. 7, 14 & WHO, 2020a \\
\hline 20 & $\begin{array}{l}\text { Protocolo situacional baseado em variáveis } \\
\text { de cenário para todo país (baixo, médio e } \\
\text { alto risco) }\end{array}$ & políticas & $\begin{array}{l}\text { Soft power } \\
\text { (A) }\end{array}$ & SCIO, 2020, pp. 23,25 & $\begin{array}{l}\text { WHO, 2020a, pp. 15-16; } \\
\text { CWI et al., 2020, p. } 10\end{array}$ \\
\hline 21 & $\begin{array}{l}\text { Composição de força comunitária e } \\
\text { voluntária ( } 4 \text { milhões de pessoas) para } \\
\text { monitoramento e apoio social }\end{array}$ & $\begin{array}{l}\text { diplomacia } \\
\text { de } \\
\text { voluntários }\end{array}$ & $\begin{array}{l}\text { Soft power } \\
\text { (A) }\end{array}$ & SCIO, 2020, p. 55 & CWI et al., 2020, p. 5 \\
\hline 22 & $\begin{array}{l}\text { Protocolo para desinfecção e ventilação de } \\
\text { locais públicos }\end{array}$ & políticas & $\begin{array}{l}\text { Soft power } \\
\text { (A) }\end{array}$ & SCIO, 2020, p. 33 & CWI et al., 2020, p. 7 \\
\hline
\end{tabular}

Fonte: elaborado pelas autoras a partir das fontes primárias e secundárias relacionadas no quadro

\section{Notas:}

(a) $\mathrm{O}$ relatório de Keqiang (2020) não tem números de páginas, mas está dividido em 8 partes, assim, a referência “pt.” refere-se à parte do relatório em que a informação está localizada.

(b) Legenda: Sharp power (D) = sharp power na variável domínio, Sharp power (I) = sharp power na variável imposição, Soft power (I) = soft power na variável influência, Soft power (A) = soft power na variável atração. 